Disponível em:

http://editora.unoesc.edu.br/index.php/race

RACE, Joaçaba, v. 16, n. 2, p. 603-632, maio/ago. 2017

\title{
OS EFEITOS DOS ROYALTIES DA MINERAÇÃO SOBRE A PROMOÇÃO DO DESENVOLVIMENTO ECONÔMICO DOS MUNICÍPIOS BAIANOS: UMA ANÁLISE DO PERÍODO DE 2009 A 2011 POR MEIO DA ABORDAGEM DEA
}

The effects of mining royalties on the promotion of economic development of the bahia counties: an analysis for the period between 2009 and 2011 by the DEA approach

Jéssica da Silva Cerqueira

E-mail: jessica_cerq@hotmail.com

Graduada em Ciências Econômicas pela Universidade Estadual de Santa Cruz; Graduanda em MBA Executivo em Consultoria e Planejamento Empresarial pela Universidade Cândido Mendes; Cursa a disciplina de Sistemas de Informações Geográficas no Programa de Pós-graduação em Economia Regional e Políticas Públicas - Mestrado na Universidade Estadual de Santa Cruz, na qualidade de aluna especial; funcionária na empresa Meta Eletrificação Rural.

Adriano Alves de Rezende

E-mail: adriano.rezende01@gmail.com Mestre em Economia pela Universidade Federal de Viçosa; Especialista em Gestão de Negócios e Empreendimentos pela Universidade Federal de Juiz de Fora; Professor no Departamento de Ciências Econômicas da Universidade Estadual de Santa Cruz.

\section{Carlos Eduardo Ribeiro Santos}

E-mail: cersantos@uesc.br

Mestre em Cultura, Memória e Desenvolvimento Regional pela Universidade do Estado da Bahia; Graduado em Economia pela Universidade Estadual de Feira de Santana; Professor no Departamento de Ciências Econômicas da Universidade Estadual de Santa Cruz. Endereço para contato: Campus Soane Nazaré de Andrade, Rodovia Jorge Amado, km 16, Salobrinho, 45662-900, Ilhéus, Bahia, Brasil.

Artigo recebido em 07 de novembro de 2016. Aceito em 01 de março de 2017. 
Resumo

Desde 2007, o setor mineral na Bahia vem elevando sua atividade e aumentando a arrecadação da Compensação Financeira pela Exploração de Recursos Minerais (CFEM) ou royalties da mineração. Assim, com este trabalho visou-se demonstrar o efeito da CFEM sobre o desenvolvimento dos municípios baianos, particularmente sobre a educação, por meio da Análise Envoltória de Dados - Data Envelopment Analysis (DEA). Com o objetivo de demonstrar o investimento eficiente dos recursos advindos da CFEM utilizaram-se como amostra 93 municípios, no período de 2009 a 2011. Foram coletados dados do Índice Firjan de Desenvolvimento Municipal (IFDM) e do Ministério de Minas e Energia. Constatou-se que a alocação eficiente da CFEM não se relaciona diretamente com seu volume. Dos municípios analisados, cinco apresentaram eficiência em sua alocação. Quanto à sua eficiência sobre educação, percebeu-se que estes são mais bem percebidos em municípios pequenos. Conclui-se que a mineração gera empregos direta e indiretamente e tende a fomentar o desenvolvimento dos municípios baianos mediante a CFEM.

Palavras-chave: Bahia. CFEM. Desenvolvimento econômico. Eficiência. IFDM.

Abstract

Since 2007, the mining sector in Bahia has increased its activity and increased the collection of the Financial Compensation for Mineral Exploration (FCME), or mining royalties. Thus, this paper aimed to demonstrate the effect of FCME on the development in the municipalities of Bahia, particularly on education, through Data Envelopment Analysis (DEA). In order to demonstrate the efficient investment of resources coming from the FCME 93 municipalities were used as sample in the period between 2009 and 2011. Data were collected from the Municipal Development Firjan Index (MDFI) and the Ministry of Mines and Energy. It was found that the efficient allocation of FCME is not directly related to its volume. From the municipalities analyzed, five had efficiency in their allocation. Regarding their the efficiency on education, it was realized that these are best perceived in small municipalities. It was concluded that mining generates direct and indirect jobs and tends to foster development in the municipalities through FCME.

Keywords: Bahia. FCME. Economic development. Efficiency. MDFI.

\section{INTRODUÇÃO}

Atualmente a Bahia pode ser considerada um polo de mineração no Brasil dada a variedade do estoque de suas jazidas minerais, fazendo com que seja o Estado mais procurado por empresas mineradoras na contemporaneidade. Prova disso foi o aumento registrado no número de requerimentos da área para a pesquisa mineral no 
Estado entre os anos 2007 e 2010, que chegaram a 14,5 mil, ultrapassando Minas Gerais, com 13,2 mil no mesmo período.

Segundo um levantamento realizado pelo Instituto Brasileiro de Mineração (Ibram), até o final de 2015 os investimentos no setor estariam estimados em US\$ 64,8 bilhões (REZENDE, 2011). Os crescentes investimentos no setor representam, na prática, uma maior produção mineral e, por conseguinte, o aumento das exportações, a geração de empregos e renda, uma maior arrecadação de tributos pelo Estado e, consequentemente, o estímulo para o crescimento e o desenvolvimento econômico do País.

Nesse contexto, no ano 2012, a Bahia figurava na quinta posição no ranking dos maiores arrecadadores da Compensação Financeira pela Exploração de Recursos Minerais (CFEM) do País e na primeira posição entre os maiores arrecadadores do Nordeste. Em relação à alocação das receitas provenientes da CFEM, alguns autores se propuseram a analisar a eficiência de determinadas regiões na alocação dessa receita. Em um estudo, Rodrigues e Silveira (2009) analisaram a eficiência na aplicação da CFEM nos municípios mineradores na região central de Minas Gerais por meio de teste $t$ para amostras independentes e da abordagem Data Envelopment Analysis (DEA). Concluíram que os municípios que recebem a CFEM apresentam superioridade nos indicadores orçamentários em relação aos municípios que não têm renda proveniente da arrecadação da CFEM. Porém, nas variáveis sociais (saúde, educação e saneamento básico) foi identificada ineficiência na alocação desse recurso financeiro por parte dos municípios arrecadadores.

Em outro estudo, Fernandes e Santos (2014) analisaram a contribuição dos recursos minerais e petrolíferos no desenvolvimento econômico dos municípios baianos, utilizando uma regressão que tem como variável dependente o Índice de Desenvolvimento Municipal (IFDM) e, como variáveis explicativas, empregam os valores da CFEM per capita e PIB per capita, entre outras. Os autores concluem, então, que existe uma relação negativa entre a arrecadação da CFEM e a do IFDM. Enríquez (2007) afirma que a maioria dos municípios mineradores não aplica o recurso de acordo com sua finalidade.

Enríquez (2007) determina em seu trabalho que essa situação se chama "armadilha do caixa único”, que é quando o recurso entra no caixa da prefeitura e é diluído nas despesas correntes (usado nas necessidades imediatas do município). Enríquez (2007) alerta, ainda, para outro padrão de uso da CFEM denominado "uso sustentado”, quando os recursos têm fins previamente definidos. Considerando-se que a legislação deixa pequena margem quanto à interpretação para a aplicação dos royal- 
ties da mineração, bem como a ausência de uma fiscalização quanto a essa aplicação, torna-se relevante investigar: quais os efeitos dos royalties da mineração na promoção do desenvolvimento econômico dos municípios que apresentam a prática dessa atividade produtiva?

Logo, o objetivo com esta pesquisa foi identificar a eficiência na alocação dos recursos decorrentes da CFEM sob a forma de incrementos no desenvolvimento municipal e, pontualmente, na educação dos municípios beneficiados pelo recurso.

A justificativa desta pesquisa reside no fato de relacionar uma maior eficiência na aplicação dessa receita considerando-se o caráter finito dos recursos minerais e o fato de sua exploração não apenas gerar danos ambientais, mas também a possibilidade de criação de externalidades positivas. O período escolhido para a análise representa, justamente, a possibilidade de uma maior inferência nesse contexto, haja vista que entre 2009 e 2011 foi o período que contemplou a disponibilidade de todas as variáveis utilizadas na análise.

Enquanto metodologia de pesquisa, seguiu-se a perspectiva da abordagem exploratória, visto que busca evidenciar as relações do uso da CFEM sobre o processo de desenvolvimento econômico. Enquanto procedimento de pesquisa, baseou-se em um método não paramétrico, utilizando ponderação estatística pela Análise Envoltória de Dados - Data Envelopment Analysis (DEA), a qual tem sido pouco explorada para analisar a mineração e seus desdobramentos, principalmente a respeito de seus efeitos sobre os municípios mineradores. As variáveis observadas foram a CFEM, o IFDM, o IFDM Educação (IFDM-E) e o Produto Interno Bruto Municipal (PIB-M), além de dados secundários disponíveis ao acesso público.

A estrutura de discussão está pautada, inicialmente, na apresentação dos fatores que estabelecem a importância e a relevância do setor extrativista mineral para a economia do Brasil e da Bahia. Em seguida, apresenta-se a CFEM como fundamento de compensação para as externalidades provenientes dessa atividade. Posteriormente, apresenta-se o modelo estatístico aplicado na análise, bem como as variáveis definidas para a sua composição. Após traçado esse caminho contextual, é apresentada a análise do modelo e seus resultados que pautam, por fim, as conclusões finais decorrentes da pesquisa.

\section{A ATIVIDADE MINERADORA NO BRASIL E NA BAHIA}

A atividade mineradora foi a grande impulsionadora do desenvolvimento da América Latina oriundo das práticas bulionistas dos países da Península Ibérica. Desde os tempos da colonização no Brasil, com a extração de ouro, ferro e diamante, a 
mineração, que também foi responsável por parte da ocupação territorial, é um dos setores produtivos mais promissores da economia nacional por ser responsável pela obtenção de matérias-primas utilizadas por indústrias metalúrgicas, siderúrgicas, petroquímicas e de fertilizantes.

O Brasil é o quinto país de maior extensão territorial do mundo e o primeiro do hemisfério Sul, apresentando a sexta maior produção mineral mundial (MINISTÉRIO DA FAZENDA, 2002). Apesar dessa estatística, segundo o Departamento Nacional de Produção Mineral (DNPM) (2014), a maior parte do País ainda não foi explorada: apenas $30 \%$ de todo o território brasileiro foi sistematicamente explorado por meio de mapeamento geológico.

Embora o País seja autossuficiente na produção de alguns minerais, em outros ele apresenta dependência externa. Segundo dados do Instituto Brasileiro de Mineração (Ibram) (2011), o Brasil importa 91\% de toda a necessidade de potássio e $51 \%$ de fosfato, minerais utilizados na fabricação de fertilizantes. Além destes, o Brasil depende, ainda, da importação de carvão mineral, cobre, zinco e enxofre, minerais considerados estratégicos para a economia.

As transformações socioeconômicas e de infraestrutura vivenciadas pelo Brasil nos últimos anos, associadas ao processo de urbanização em países emergentes e ao fortalecimento das economias mundiais, têm impulsionado o aumento da demanda por minerais e, consequentemente, o valor da Produção Mineral Brasileira (PMB).

Grande parte das exportações minerais brasileiras está concentrada no minério de ferro, segmento no qual o Brasil é o segundo maior produtor e exportador mundial. Dos 180 bilhões de toneladas de reservas mundiais, 29 bilhões estão situados no Brasil. De acordo com o Instituto Brasileiro de Mineração (2012), dos 390 milhões de toneladas de minério de ferro produzidas no Brasil em 2011, cerca de 85\% (330 milhões de toneladas) da produção foram exportados, tendo como principal destino a China.

Segundo categorização da Classificação Nacional de Atividades Econômicas (CNAE 2.1), seção B, (IBGE, 2015), a atividade de mineração é representada pelas indústrias extrativas, fazendo parte desta a extração de carvão mineral, de petróleo e gás natural, além da extração de minerais metálicos e não metálicos, podendo ser realizadas em minas subterrâneas, a céu aberto ou em poços. A indústria extrativa compreende também as atividades de apoio à extração de minerais.

Ainda segundo a CNAE 2.1, encontram-se no segmento dos minerais metálicos minério de ferro e outros minerais metálicos não ferrosos, como manganês, estanho, alumínio, entre outros. No segmento dos minérios não metálicos está a extração 
de pedra, argila, areia ${ }^{1}$ e outros utilizados para a fabricação de adubos e fertilizantes, como sal marinho e sal gema (IBGE, 2015).

\section{A MINERAÇÃO NO ESTADO DA BAHIA}

Nesse contexto, o Estado da Bahia é o quinto maior produtor mineral do Brasil. E no ranking das exportações do Estado, a mineração ocupa a $12^{a}$ posição (COMPANHIA BAIANA DE PESQUISA MINERAL, 2013). No que se refere ao comércio exterior de bens minerais, o Estado atingiu, em 2015, um saldo positivo de US\$ 1,5 bilhão (SECRETARIA DE DESENVOLVIMENTO ECONÔMICO DO ESTADO DA BAHIA, 2014).

Grande parte dos municípios baianos conta com alguma atividade relacionada à mineração, metálica ou não metálica. A maioria desses municípios está localizada na região conhecida como semiárido baiano, na qual, além do solo pouco fértil e da irregularidade de chuvas, há escassez de empregos. Entretanto, essa realidade está mudando com a ampliação de projetos de mineração na região (fruto da descoberta de novos polos de extração mineral após 2005).

Apesar de ocupar, atualmente, a quinta posição no ranking nacional da produção mineral, com os crescentes projetos de exploração, o Estado tem potencial para se tornar o terceiro maior produtor mineral, ficando atrás apenas de Minas Gerais e Pará. Segundo o Departamento Nacional de Produção Mineral (DNPM), em 2013, existiam cerca de 340 empresas de mineração que atuavam em 100 municípios, e, nesse contexto, a quantidade de requerimentos para a pesquisa mineral reafirma o interesse das empresas pelo potencial mineral baiano (DEPARTAMENTO NACIONAL DE PRODUÇÃO MINERAL, 2013). Inclusive, segundo Correia (2011), de 2007 a 2009 a Bahia liderou em relação a requerimentos de pesquisa no País, desbancando Minas Gerais, que reassumiu a posição em 2010.

Além do ferro, níquel, ouro e bauxita, o Estado da Bahia conta com cerca de 40 outras substâncias minerais exploráveis, sendo o maior produtor nacional de urânio, cromo, sal gema, magnesita, talco e barita. Ocupa também o segundo lugar na produção de cobre, grafita e prata e é o terceiro em ouro, rochas ornamentais e gás natural. Recentemente foi descoberto em seu território o tálio, no Município de Bar-

\footnotetext{
${ }^{1}$ Comum em grande parte dos municípios brasileiros, o que faz com que uma boa parte dele apresente receitas oriundas da CFEM, mesmo sem que haja instaladas, neles, grandes empresas de mineração e extração.
} 
reiras, metal raro e estratégico, de alto valor (US\$ 6 por grama) e explorado comercialmente em apenas dois países: China e Cazaquistão (INSTITUTO BRASILEIRO DE MINERAÇÃO, 2011).

Para Correia (2011), a Produção Mineral Baiana Comercializada (PMBC) vem evoluindo desde 2007, batendo recorde em 2010, quando atingiu 1,7 bilhão de toneladas. A maioria da produção mineral baiana é comercializada na fase bruta, sendo esta responsável por 1,2\% do PIB da Bahia. Ao lado do aumento da PMBC está o aumento da arrecadação proveniente da CFEM, como demonstrado na Tabela 1.

Tabela 1 - Evolução da CFEM no Estado da Bahia de 2004 a 2013 (R\$)

\begin{tabular}{crr}
\hline Ano & Distribuição da CFEM & Variação percentual CFEM $(\boldsymbol{\Delta} \%)$ \\
\hline 2004 & $8.985 .488,08$ & - \\
2005 & $9.779 .463,32$ & 8,84 \\
2006 & $13.240 .972,93$ & 35,4 \\
2007 & $13.265 .844,22$ & 0,19 \\
2008 & $17.030 .183,81$ & 28,38 \\
2009 & 18.121 .594 .25 & 6,41 \\
2010 & $26.979 .958,76$ & 48,88 \\
2011 & $34.092 .314,72$ & 26,36 \\
2012 & $37.260 .071,39$ & 9,29 \\
2013 & $47.532 .271,89$ & 27,57 \\
\hline Fonte: adaptada do Departamento Nacional de Produção Mineral (2014).
\end{tabular}

A Bahia, em 2013, posicionava-se entre os maiores arrecadadores da CFEM do País, ficando atrás de Minas Gerais, Pará, Goiás e São Paulo, e representando 1,88\% da arrecadação total do Brasil. No ano 2013 o cobre foi responsável por R\$ 17.116.144,85 do total arrecadado pelo Estado, e o minério de níquel foi responsável por R\$ 8.531.593,71 (DEPARTAMENTO NACIONAL DE PRODUÇÃO MINERAL, 2014). Os principais municípios arrecadadores na Bahia foram: Itagibá, Andorinha, Jacobina, Salvador, Barrocas, Campo Formoso, Caetité, Medeiros Neto, Vitória e Conquista e Feira de Santana. E, em comparação à arrecadação proveniente da CFEM, esta aumentou quase 429\% entre 2004 e 2013.

A análise do setor mineral e de seu desempenho pode ser feita, inclusive, por meio da avaliação dos níveis de empregos gerados pelo setor. Em 2013, o Estado em que o setor mais empregava era Minas Gerais, com 31,3\% do total de trabalhadores empregados, seguido de São Paulo e Pará, respectivamente com 9,4\% e 9\%. Assim, a Bahia era o quinto Estado onde mais se empregava no setor. Do total de empregos gerados no Estado, 5,9\% é absorvido pela indústria extrativa mineral (DEPARTAMEN- 
TO NACIONAL DE PRODUÇÃO MINERAL, 2009). E, de acordo com o Instituto Brasileiro de Mineração (2012), o efeito multiplicador de empregos no setor extrativo mineral é de 1:13 (um para treze), ou seja, para cada emprego direto gerado no setor, são ofertadas outras 13 vagas ao longo da cadeia produtiva. Esse efeito é demostrado na Tabela 2 para os municípios baianos com maior volume de arrecadação (acima de R\$ 1 milhão) de CFEM entre os anos 2009 e 2011.

Tabela 2 - Efeito multiplicador estimado do setor extrativo mineral na geração de empregos baianos nos anos 2009 a $2011^{21}$

\begin{tabular}{lrrrrrr}
\hline & \multicolumn{1}{c}{ Empregos diretos } & \multicolumn{3}{c}{ Empregos indiretos } \\
\hline & $\mathbf{2 0 0 9}$ & $\mathbf{2 0 1 0}$ & $\mathbf{2 0 1 1}$ & $\mathbf{2 0 0 9}$ & $\mathbf{2 0 1 0}$ & $\mathbf{2 0 1 1}$ \\
\hline Brumado & 25 & 39 & -5 & 325 & 507 & -65 \\
Itagibá & 383 & 297 & 181 & 4979 & 3861 & 2353 \\
Jacobina & -25 & 22 & 34 & -325 & 286 & 442 \\
Jaguarari & 16 & 50 & 220 & 48 & 650 & 2860 \\
\hline Fonte: os autores. & & & & & &
\end{tabular}

Dos municípios que mais obtiveram renda a partir da CFEM, Itagibá foi o que mais gerou empregos. O Município, que tinha a agricultura e a pecuária como base de sua economia, conta, atualmente, com o mais novo polo de exploração de minério de níquel do Brasil. Dos anos analisados, 2009 foi o que mais gerou vagas, quando foram criados 383 empregos diretos e 4.979 outros postos de trabalho, ao longo da cadeia produtiva (Tabela 2), ano, inclusive, em que ocorreu o início do processo de exploração mineral no Município.

\section{A COMPENSAÇÃO FINANCEIRA PELA EXPLORAÇÃO DE RECURSOS MINERAIS (CFEM)}

A CFEM possui papel de destaque no que no que se refere à atividade econômica da mineração, principalmente em momentos em que o processo de crescimento e desenvolvimento econômico vem ganhando destaque na sociedade, sobretudo nas questões do desenvolvimento sustentável. Assim, em relação à maioria das atividades econômicas, a mineração tem uma especificidade: seu caráter exaurível. Esse caráter

\footnotetext{
${ }^{2}$ Os dados para empregos indiretos foram estimados considerando a proporção de 1:13, indicada pelo Instituto Brasileiro de Mineração (2012).
} 
lhe confere, segundo o Ministério de Minas e Energia (2009), um considerável custo de oportunidade.

Esse custo de oportunidade consiste no trade-off entre explorar imediatamente ou postergar essa exploração, além do caráter permanente das alterações ao meio ambiente que a atividade ocasiona. De acordo com Monteiro (2004), em razão das peculiaridades da atividade mineral, há a aceitação quase generalizada da ideia de que a mineração deve ser taxada como uma maneira de internalizar as externalidades ambientais e sociais provocadas pela extração mineral e pelo uso de um recurso que não mais estará à disposição da sociedade, assim, esta deve receber uma compensação pela perda permanente daquele bem.

Antes da promulgação da Constituição Federal de 1988, a taxação sobre recursos minerais era feita por meio do Imposto Único sobre Mineral (IUM³). Ao passo que se extinguiu o IUM, a Constituição Federal de 1988 estabeleceu que todos os recursos minerais, inclusive os do subsolo, pertencem à União, assegurando aos Estados, Distritos Federais e Municípios a participação financeira na exploração de recursos minerais oriundos dos repasses deles provenientes.

\begin{abstract}
É assegurada, nos termos da lei, aos Estados, ao Distrito Federal e aos Municípios, bem como a órgãos da administração direta da União, participação no resultado da exploração de petróleo ou gás natural, de recursos hídricos para fins de geração de energia elétrica e de outros recursos minerais no respectivo território, plataforma continental, mar territorial ou zona econômica exclusiva, ou compensação financeira por essa exploração. (BRASIL, 1988, p. 1).
\end{abstract}

Assim, por meio da Lei n. 7.990, de 1989, foi instituída a Compensação Financeira pela Exploração de Recursos Minerais (CFEM), gerada a partir do momento que o produto mineral é retirado da jazida, mina, salina ou qualquer outro depósito, assim como sua transformação industrial ou consumo por parte do minerador. As alíquotas da CFEM variam conforme a substância, podendo chegar a 3\% (sobre o minério de alumínio, manganês, sal gema e potássio, por exemplo). O cálculo da CFEM

\footnotetext{
${ }^{3}$ Incidia somente uma vez sobre qualquer uma das operações relativas à mineração, desde a extração ao consumo das substâncias, excluindo a cobrança de outros tributos pela União, Estado ou município. De acordo com a Lei Constitucional n. 4.425, de 08 de outubro de 1964, os Estados, Territórios e Distritos Federais deveriam aplicar o recurso em obras ou projetos que beneficiassem o setor mineral, já os recursos destinados aos Municípios deveriam ser investidos na educação, na saúde pública e na assistência social.
} 
é baseado no faturamento líquido da venda do produto mineral. Esse faturamento líquido é a receita obtida com a venda, deduzidos Programa de Integração Social (PIS), Contribuição para o Financiamento da Seguridade Social (Cofins), Imposto sobre Circulação de Mercadorias e Serviços (ICMS) e as despesas com transportes e seguros. Logo, comporta-se como um royalty ad valorem sobre a produção mineral (MINISTÉRIO DE MINAS E ENERGIA, 2009).

É de competência do Departamento Nacional de Pesquisa Mineral (DNPM) baixar normas, administrar e fiscalizar a arrecadação da CFEM. Essa compensação é dividida entre a União, ${ }^{4}$ Estado e municípios, cada um recebendo respectivamente 12\%, 23\% e 65\% (DEPARTAMENTO NACIONAL DE PRODUÇÃO MINERAL, 2014). Os percentuais recebidos pelos órgãos devem ser convertidos em benefícios para a comunidade local, como projetos de infraestrutura, qualidade ambiental, saúde e educação, o que lhe atribui um caráter de destinação ao desenvolvimento econômico e social desses espaços e do País. ${ }^{5}$

Em junho de 2013 foi enviado ao Congresso Nacional o projeto que propõe o Novo Marco Regulatório da Mineração (Projeto de Lei n. 5.807/2013) o qual, se aprovado, substituirá o atual Código da Mineração, que vigora desde 1967. Entre as propostas de mudança no setor está a reformulação do atual modelo de Compensação Financeira pela Exploração de Recursos Minerais, na qual o cálculo da CFEM que atualmente é baseado no faturamento líquido da venda do produto mineral passaria a ser baseado na receita bruta da venda deduzidos os tributos efetivamente pagos incidentes sobre a comercialização do bem mineral. Além disso, o valor das alíquotas da CFEM, que chega a 3\%, alcançaria os 4\% (MINISTÉRIO DE MINAS E ENERGIA, 2013).

\section{O MÉTODO E AS VARIÁVEIS DE ANÁLISE}

Em relação ao método estatístico aplicado à pesquisa, foram utilizadas, de forma encadeada, duas ferramentas de análise: um método não paramétrico e outro paramétrico. O método não paramétrico empregado foi a Análise Envoltória de Dados

\footnotetext{
${ }^{4}$ A cota-parte da União é rateada ao DNPM (9,8\%), ao Fundo Nacional de Desenvolvimento Científico e Tecnológico (FNDCT) (2\%) e ao Instituto Brasileiro do Meio Ambiente e dos Recursos Naturais Renováveis (Ibama) $(0,2 \%)$.

${ }^{5}$ É vedada a utilização do recurso no pagamento de dívidas ou de quadro de pessoal, com exceção ao custeio de despesas com manutenção e desenvolvimento do ensino, especialmente na educação básica pública em tempo integral (BRASIL, 1989).
} 
- Data Envelopment Analysis (DEA) com o objetivo de demonstrar a eficiência dos municípios baianos quanto à alocação dos recursos advindos da CFEM de acordo com as proposições legais dela. Esse método, segundo Ferreira e Gomes (2009), teve início com as reflexões de métodos matemáticos de programação que buscavam alocar, de forma eficiente, os recursos na economia.

\subsection{VARIÁVEIS}

A análise do desenvolvimento econômico dos municípios baianos mediante eficiência na alocação dos recursos da Compensação Financeira pela Exploração de Recursos Minerais (CFEM) ocorreu por meio de três variáveis. A primeira foram os repasses dos valores efetivos de CFEM (ou como também é conhecida - royalties da mineração) efetuados pela União no período de 2009 a 2011. Os dados estão disponíveis no Departamento Nacional de Produção Mineral (DNPM), órgão diretamente vinculado ao Ministério de Minas e Energia (MME), com periodicidade anual, com os valores expressos em milhões de reais, de forma a não destoarem tanto dos coeficientes de desenvolvimento utilizados quanto das variáveis explicativas.

Inicialmente, levantou-se que os dados disponíveis para os municípios baianos que receberam partidas financeiras da CFEM estavam compreendidos entre 2005 e 2011. Isso resultou em uma amostra inicial de 143 municípios. Entretanto, foi observado que nesses municípios os valores recebidos eram intermitentes ao longo do período. Assim, para melhorar a qualidade de resposta do modelo, foram excluídos os municípios que, dentro do período analisado, não receberam repasse de recursos por mais de quatro anos, o que resultou em uma amostra de 93 municípios fundamentais para a análise. Esse recorte temporal justifica-se também por compreender a disponibilidade de dados fidedignos para todas as variáveis utilizadas nesta pesquisa.

Enquanto segunda variável fundamental à análise e que possibilitou a verificação da potencial relação entre as demais variáveis e o processo de desenvolvimento econômico dos municípios em questão, utilizou-se o Índice Firjan de Desenvolvimento Municipal (IFDM), calculado pela Federação das Indústrias do Estado do Rio de Janeiro (Firjan). Evidencia-se que análises desse tipo se utilizam do Índice de Desenvolvimento Humano (IDH) como parâmetro, e seus desdobramentos são respaldados por Nogueira e Ramos (2013), ao sinalizarem que o IDH representa uma proxy da reversão dos recursos decorrentes dos royalties da mineração em benefícios à educação, à saúde (longevidade) e à renda dos municípios. 
Entretanto, deve-se destacar que se optou pela utilização do IFDM ${ }^{65}$ em detrimento do IDH-M, convencionalmente usado em trabalhos dessa natureza, pois se considerou este tanto quanto o outro, proxies adequadas para mensurar o desenvolvimento econômico. Ademais, segundo Daniel et al. (2011), o IFDM apresenta uma metodologia análoga ao IDH-M, porém engloba um número maior de variáveis, além de ter uma periodicidade anual, o que permitiu determinar o recorte temporal das variáveis entre os anos 2009 e 2011 para todos os dados da amostra.

Por fim, a terceira e última variável fundamental para a aplicação da análise foi o Produto Interno Bruto Municipal (PIB-M). Para maior consistência das informações e diminuição de um possível viés, foram utilizados os valores apurados do PIB-M do período de 2009 a 2011 em milhões de reais. As informações foram obtidas do Instituto Brasileiro de Geografia e Estatística (IBGE) e referem-se a cada um dos 93 municípios utilizados neste estudo. Ressalta-se que a definição do período observado ocorreu, fundamentalmente, pela disponibilidade de dados fidedignos e de livre acesso.

\subsection{A ANÁLISE ENVOLTÓRIA DE DADOS (DEA)}

A aplicação dos modelos prevê a confirmação da premissa de que a utilização do CFEM para investimento direto na educação, conforme determinado em lei, provoca externalidades positivas nos outros indicadores desagregados, e, por conseguinte, impacta diretamente no indicador geral (IFDM) que representa o processo de desenvolvimento econômico.

A abordagem por Análise Envoltória de Dados - Data Envelopment Analysis (DEA) ou Frontier Analysis) baseia-se em modelos matemáticos não paramétricos, isto é, não utiliza inferências estatísticas ou se apega a medidas de tendência central, testes de coeficientes ou formalizações de análise de regressão (FERREIRA; GOMES, 2009).

O objetivo principal da DEA é avaliar a eficiência de cada Unidade Tomadora de Decisão - Decision Making Units (DMU) e verificar quais delas estão inseridas

\footnotetext{
${ }^{6}$ Tal qual o IDH-M, varia de 0 (mínimo) a 1 ponto (máximo) para classificar o nível de desenvolvimento de cada município. Contudo, difere-se do IDH por classificar seus resultados em quatro categorias, conforme designação da Firjan (2015): baixo desenvolvimento se o IFDM for entre 0 e 0,4; desenvolvimento quando os valores referenciais forem entre 0,41 e 0,6; desenvolvimento moderado se entre 0,61 e 0,8 e, por fim, a última faixa que representa os municípios com desenvolvimento quando seu indicador está entre 0,81 e 1,0 .
} 
na fronteira de possibilidade de produção, ou seja, verificar se o desempenho dessas organizações ou atividades, do ponto de vista da eficiência técnica, é ótimo (FERREIRA; GOMES, 2009; DINIZ NETTO; ANGULO MEZA, 2009). Nesta pesquisa, como o método $D E A$ foi utilizado para mensurar a eficiência relativa de cada município do Estado da Bahia beneficiado com os royalties da mineração, esses municípios constituem as DMUs do método.

A DEA permite verificar quais são as DMUs de referência (benchmarks), que são as unidades que adotam as melhores práticas, ou seja, são as DMUs mais eficientes. A partir destas, é possível construir a Fronteira de Possibilidade de Produção (FPP) derivada dessa amostra representativa.

As unidades que formam a FPP servirão de benchmarks para as DMUs consideradas ineficientes, possibilitando a estas últimas se projetarem para a FPP, tendo como referência seus benchmarks por meio de contração radial ou combinação linear. O método DEA necessita que as DMUs utilizadas sejam homogêneas, ou seja, devem atuar no mesmo ramo de atividade, utilizar os mesmos inputs e produzir os mesmos outputs (DANIEL et al., 2011).

Para efeito de análise, no método DEA existem dois modos de orientação, um com orientação input e outro com orientação output. Nos modelos orientados a input, os níveis de output (produto) permanecem constantes, e os de input (insumos) variam a fim de atingir a fronteira de produção. Nos modelos orientados a output, o nível de input permanece constante, enquanto o nível de output varia para atingir a fronteira de possibilidade de produção, que nesse caso é côncava (DANIEL et al., 2011).

Nesta análise, foi utilizado um modelo de retornos crescentes com orientação output (conforme APÊNDICE A) dado que as variáveis utilizadas e suas características se ajustam melhor a esse modelo, logo, melhorando sua capacidade de resposta. Assim, cabem algumas considerações adicionais sobre ele. Angulo Meza et al. (2007) afirmam que o modelo BCC avalia situações de eficiência de produção com variação de escala e desconsidera a existência de proporcionalidade entre inputs e outputs. De acordo com Ferreira e Gomes (2009), o modelo BCC usa, para cada DMU, o Problema de Programação Linear (PPL) no qual introduz uma restrição de convexidade ao modelo CCR e pode ser representado conforme a Equação 1. 


$$
\operatorname{Max} h_{\phi}=\sum_{j=1}^{n} u_{j} y_{j 0}-u,
$$

Sujeito a

$$
\sum_{i=1}^{m} p_{i,} x_{i 0}=1
$$$$
\sum_{j=1}^{3} u_{j} y_{i k}-\sum_{i=1}^{m} v_{k}, x_{i k}-u_{s} \leq 0, \quad k=1, \ldots, n
$$

$$
\begin{aligned}
& u_{1}, x_{l} \geq 0 \quad \forall x, y \\
& u \in \mathbb{R}
\end{aligned}
$$

Nesse modelo, para cada DMU analisada, a eficiência é dada por $h_{o}, x_{i k}$ que representa o input $i$ da DMU e $k, y_{j k}$ representa o output $j$ da DMU $k, u_{j}$. O $v_{i}$ representa os pesos dados aos inputs $i$ e aos outputs $j$, respectivamente; $u_{*}$ é um fator de escala (quando positivo, indica que a DMU está em região de retornos decrescentes de escala, quando negativo, os retornos de escala são crescentes). Se $h_{o}$ é igual a 1, a $\mathrm{DMU}_{\mathrm{o}}$ em análise é considerada eficiente.

No PPL (1) as variáveis de decisão são e $v_{i}$, $u_{j}$ e $h_{o}$. No modelo BCC uma DMU é eficiente se, na escala em que opera, é a que melhor aproveita os inputs de que dispõe. Já no modelo CCR, uma DMU é eficiente quando apresenta o melhor quociente de outputs com relação aos inputs, ou seja, aproveita melhor os inputs sem considerar a escala de operação da DMU (ANGULO MEZA et al., 2007). Tais argumentos reforçam a opção de utilização do modelo BCC neste trabalho, principalmente por respaldar o emprego da razão anual entre CFEM e PIB () como input, uma vez que a análise ocorreu no período de 2005 a 2011. Assim, no Quadro 1 observam-se as variáveis do modelo.

Quadro 1 - Variáveis do modelo DEA BCC

\begin{tabular}{|l|l|l|}
\hline \multicolumn{1}{|c|}{ Variável } & \multicolumn{1}{c|}{ Descrição e característica } \\
\hline Input & $\begin{array}{l}\text { Recursos Royalties } \\
\text { da Mineração }\end{array}$ & $\begin{array}{l}\text { Essa razão mitiga possíveis distorções na aplicação do método } \\
\text { DEA. Por se tratar de um período de três anos e por não se dispor } \\
\text { de estimativas precisas quanto à população, essa razão é tida como } \\
\text { suficiente à análise. O resultado indica o percentual da participação } \\
\text { da CFEM dentro do PIB municipal e tem seus valores expressos } \\
\text { em números decimais. }\end{array}$ \\
\hline
\end{tabular}




\begin{tabular}{|c|c|c|}
\hline & Variável & Descrição e característica \\
\hline Output 1 & $\begin{array}{l}\text { Índice Firjan de } \\
\text { Desenvolvimento } \\
\text { Municipal Educa- } \\
\text { cional } \\
\text { IFDME }\end{array}$ & $\begin{array}{l}\text { Indicador de melhoria do desenvolvimento no município “i” no } \\
\text { período “t” para a perspectiva “educação”, calculado anualmente } \\
\text { pela Firjan. Sua utilização como output do modelo DEA BCC está } \\
\text { no fato dos recursos da CFEM serem destinados, em Lei, para a } \\
\text { Educação. Variável proxy da melhoria do sistema educacional. }\end{array}$ \\
\hline Output 2 & $\begin{array}{l}\text { Índice Firjan de } \\
\text { Desenvolvimento } \\
\text { Municipal } \\
\text { IFDME }\end{array}$ & $\begin{array}{l}\text { Indicador de melhoria efetiva do desenvolvimento no município “i” } \\
\text { no período "t”, calculado anualmente pela Firjan. } \\
\text { Utilizado como output no modelo DEA BCC no intuito de mensu- } \\
\text { rar o impacto do recurso da CFEM sob o desenvolvimento muni- } \\
\text { cipal. Variável proxy da melhoria do desenvolvimento municipal, } \\
\text { dado que este não é facilmente observável. }\end{array}$ \\
\hline
\end{tabular}

Fonte: os autores.

O modelo DEA BCC foi aplicado individualmente, utilizando-se o input $R R M_{t}$ contra os outputs IFDM $_{\mathrm{t}}$ e IFDME $\mathrm{E}_{\mathrm{t}}$ a fim de demonstrar os efeitos da CFEM sobre o desenvolvimento municipal, considerando seu percentual sobre o PIB dos municípios estudados.

Os modelos $D E A$, por produzirem avaliações benevolentes, geralmente resultam em um grande número de DMUs eficientes. Além disso, em decorrência das características matemáticas do modelo BCC, as DMUs que têm o menor valor de um dos inputs ou o maior valor de um dos outputs são consideradas eficientes, mesmo que as relações com as demais variáveis não sejam as melhores (ALI, 1993). Essas DMUs são chamadas de falsamente eficientes ou eficientes à partida.

Existem vários métodos para melhorar a discriminação em modelos DEA (ADLER; SINUANY-STERN, 2002; ANGULO MEZA; LINS, 2002; LETA et al., 2005). Um deles, que tem a vantagem adicional de eliminar as DMUs falsamente eficientes no modelo BCC, é a fronteira invertida. Esse tipo de fronteira, baseada na inversão de inputs e outputs, é apresentada em Lins et al. (2007).

O uso da fronteira invertida como ferramenta para aumentar a discriminação entre as DMUs pode ser visto em Angulo Meza et al. (2005), Soares et al. (2005) e Gomes et al. (2006). A fronteira invertida com esse objetivo é utilizada na construção de um índice chamado de Î́ndice de Eficiência Composta. Ele é definido como a média aritmética da eficiência em relação à fronteira de eficiência padrão e o complemento da eficiência em relação à fronteira invertida, como visto na Equação 2. O uso do complemento justifica-se pelo fato de a fronteira invertida gerar uma medida de ineficiência.

$$
\text { Eficiência Composta = Eficiência Padrão+(1-Eficiência Invertida) }
$$


Para se obter um índice em que as unidades eficientes têm o valor de 1, é feita a normalização da eficiência composta ao dividirem-se seus valores pela maior de todas as medidas de eficiência compostas. O software livre SIAD 3.0, utilizado neste trabalho, gera o resultado de Eficiência Composta Ponderada automaticamente. Esta, por sua vez, subsidiou a análise proposta neste trabalho.

\section{ANÁLISE DOS RESULTADOS}

Atualmente o IFDM é uma importante ferramenta na decisão de políticas públicas e de investimentos entre os municípios baianos por refletir não somente a situação atual dos municípios, como também os esforços na busca por melhores resultados (ERVILHA; ALVES; GOMES, 2013). Dentro desse contexto, por meio da utilização do $D E A$, buscou-se analisar se o fato de os municípios baianos obterem renda proveniente da CFEM contribui para seu desenvolvimento mediante a alocação eficiente desse recurso. A premissa considerada é de que a eficiência na alocação da CFEM impacta positivamente o IFDM-E, que, por sua vez, causa externalidades positivas nos outros agregados do índice geral, como renda e saúde do município e, consequentemente, é captado por ele (IFDM).

Na Bahia o destaque é Salvador, região mais produtiva do Estado e que possui diversas atividades relacionadas à mineração, tanto de minerais metálicos quanto de não metálicos. Nesse sentido, quanto à eficiência no IFDM do município, este foi considerado eficiente, encontrando-se, em todo o período observado, na fronteira de eficiência no que se refere à aplicação do recurso. Já no interior, o Município de Irecê evidenciou-se como eficiente para o IFDM-E no ano 2009, e Lauro de Freitas apresentou-se eficiente no IFDM. A partir desse ano, observa-se o aumento da distância entre as linhas que representam o IFDM-E e o IFDM, como exibido no Gráfico 1.

Nesse contexto, foi destacado o Município de Ibitiara, que apresentou eficiência no IFDME de 0,91 e, no IFDM, um score de 0,52. Nesse mesmo ano o Município obteve apenas $\mathrm{R} \$ 654,35$ resultantes da CFEM, correspondendo a aproximadamente 0,001\% do PIB municipal. Esse valor foi inferior ao recebido em 2008, quando o Município arrecadou R\$ 15.907,96 (aproximadamente 0,03\% do PIB Municipal), o que reforça a constatação de que o volume de CFEM arrecadado pelos municípios não tem relação direta com o nível de eficiência na alocação deste.

Por um lado, o resultado observado em Ibitiara tende a demonstrar uma preocupação de certas prefeituras em melhorar e aperfeiçoar, independentemente da ori- 
gem do recurso, o sistema municipal de educação, haja vista os resultados obtidos pelo IFDM-E em relação aos irrisórios valores recebidos pela CFEM. Por outro lado, mediante recursos limitados, o empenho na melhoria da educação tende a reduzir as dotações para outros investimentos prioritários, como a sociedade, no curto prazo.

Gráfico 1 - Eficiência no IFDM-E e IFDM dos municípios baianos no período de 2009

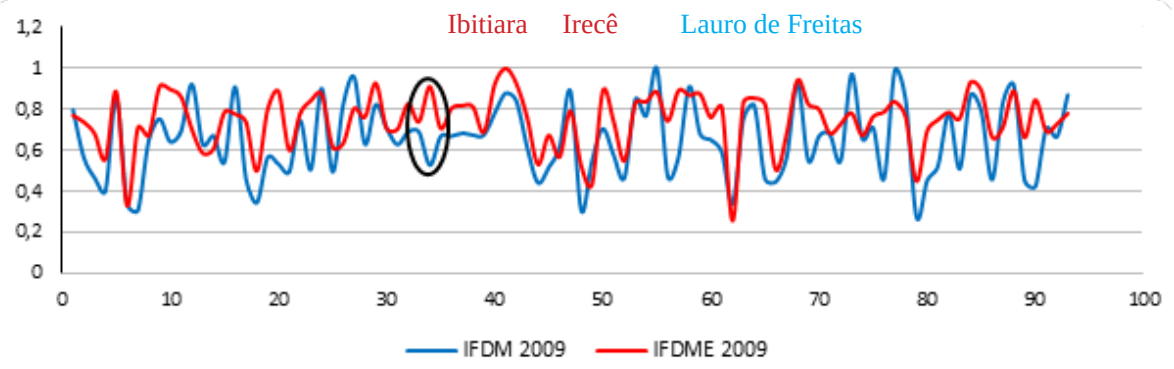

Fonte: os autores.

Em 2010, os Municípios de Irecê e Lauro de Freitas continuaram sendo eficientes, como apresentado no Gráfico 2. O Município de Ibitiara apresenta score bem próximo da fronteira de eficiência no IFDM-E, porém, continua com valor baixo no IFDM, o que causa distância entre as linhas que representam os índices. Mais do que uma simples distância, isso significava que, apesar de o Município estar sendo eficiente no IFDM-E, ele apresenta ineficiência quanto à alocação da CFEM para a geração de benefícios nos outros segmentos do índice de IFDM.

Gráfico 2 - Eficiência no IFDM-E e IFDM dos municípios baianos no período de 2010

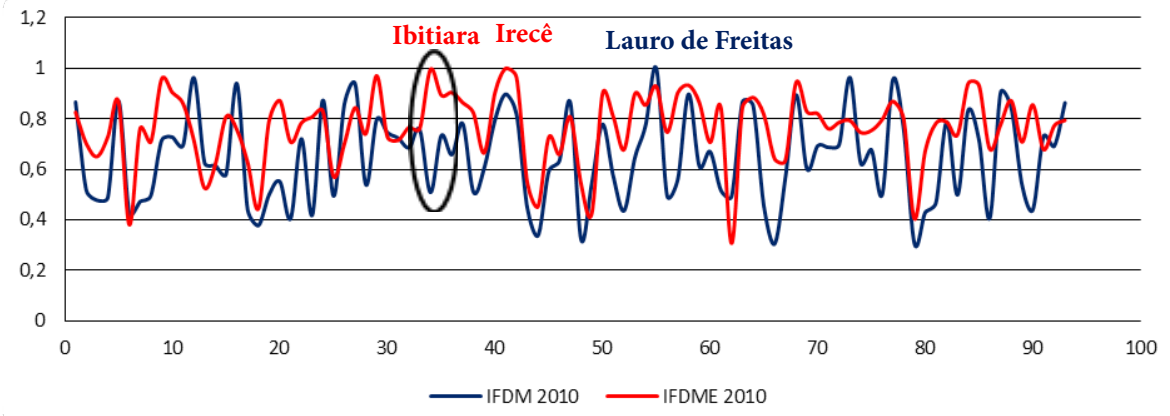

Fonte: os autores.

O desempenho dos municípios baianos quanto à eficiência na alocação da CFEM e à geração de benefícios para a população, em 2011, apresentou comporta- 
mento diferente dos outros anos. O Município de Mata de São João vinha apresentando nos anos em análise (desde o primeiro ano) score de eficiência igual a 0,61 e no referente ao IFDM-E apresentou em 2011 score de eficiência igual a 1, caracterizando-se como município eficiente na alocação da CFEM. Quanto à eficiência no IFDM, quatro Municípios atingiram score igual a 1: Camaçari, Candeias, Lauro de Freitas e Porto Seguro (Gráfico 3).

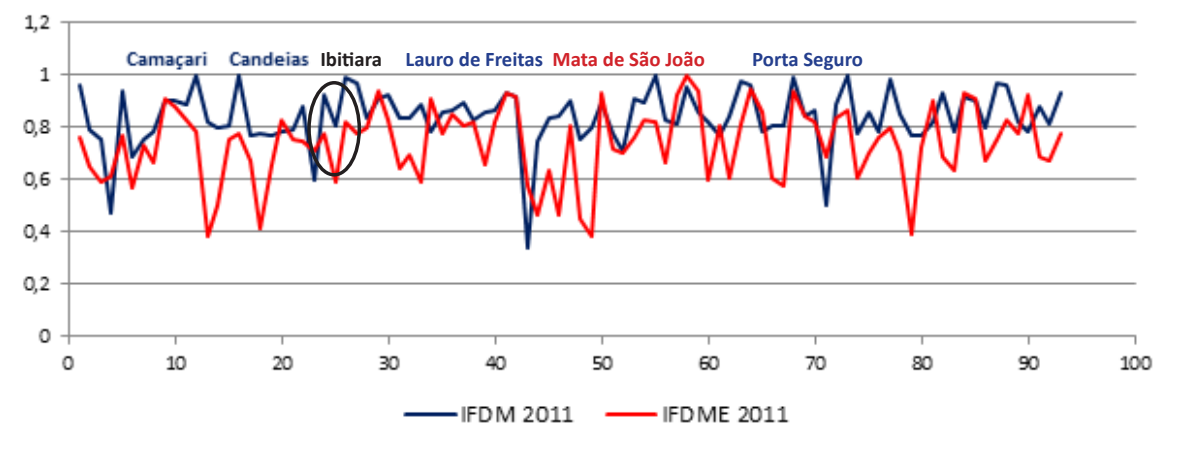

Fonte: os autores.

Embora uma quantidade maior de municípios tenha alcançado a eficiência, em 2011 a diferença nos índices encontrada nos municípios não eficientes também foi maior. O Município de Camamu, por exemplo, apresentou score de eficiência no IFDM-E de 0,38, ao passo que o score de eficiência no IFDM foi de 0,81. É relevante atentar para Itagibá, Município que apresentou menor score de eficiência no IFDM, apesar de ter sido, nesse ano, o que mais arrecadou CFEM no Estado (R\$ 6.630.491,03), segundo o Departamento Nacional de Produção Mineral (2014).

No contexto geral, dos 93 municípios analisados, poucos apresentaram eficiência na alocação do recurso da CFEM especificamente no que se trata do seu investimento no segmento educação, sendo apenas quatro: Senhor do Bonfim, Porto Seguro, Irecê e Mata de São João, os quais orbitaram próximo à fronteira de eficiência (100\%), contudo, sem atingi-la. Curiosamente, o Município de Senhor do Bonfim é considerado pequeno, segundo o número de habitantes; sua economia é baseada na agricultura, pecuária, comércio e extração mineral, produzindo cobre, manganês e volfrâmio. Contudo, os repasses em valores médios anuais para o período de 2009 a 2011 não ultrapassaram R\$ 2.500,00.

De maneira geral, valendo-se da observação do Município de Ibitiara no Gráffico 3, por exemplo, ao longo dos três anos analisados, é perceptível que o empenho 
feito pelo Município em prol da melhoria de seu sistema educacional gerou efeitos positivos nos demais agregados que compõem o IFDM, pois a distância entre as curvas dos dois índices diminuiu. Quantitativamente, a diferença dos scores do IFDM-E e do IFDM, para o período de 2009 a 2011, foi de, respectivamente, 0,382, 0,486 e 0,128.

Já o Município de Irecê atingiu a eficiência plena durante três anos consecutivos. Ele também é tido como pequeno, se considerado o número de habitantes, e reconhecido pelo grande potencial agrícola, agropecuário e de prestação de serviços. Contudo, ele não apresenta relevância produtiva no segmento mineral, a não ser dos não metálicos.

Assim, quanto à eficiência no IFDM, cinco municípios apresentaram score igual a um: Lauro de Freitas, Salvador, Camaçari Candeias e Porto Seguro. Já quanto à estrutura dos municípios considerados eficientes, a maioria deles é de porte médio, segundo o número de habitantes, pela classificação adotada pelo Instituto Nacional do Semiárido (Insa) (2016). Percebe-se que os efeitos causados pela CFEM sobre o IFDM-E são mais bem percebidos em municípios pequenos. Uma justificativa para o fato é que municípios menores contam com serviços de saúde de municípios maiores, podendo ser destinada para a educação uma maior parte do valor arrecadado por meio da CFEM. Essa percepção é corroborada pelos resultados encontrados por Ervilha, Alves e Gomes (2013) em um estudo sobre o desenvolvimento municipal e a eficiência dos gastos públicos na Bahia.

Nos municípios maiores, por sua vez, os impactos da CFEM são percebidos em menor magnitude, visto que esses municípios contam com uma base econômica mais diversificada e não são tão dependentes de recursos/repasses governamentais. Assim, tem-se que os municípios menores, dadas as restrições de recursos, tendem a ser mais eficientes na utilização dos recursos da CFEM.

\section{CONSIDERAÇÕES FINAIS}

Diante do exposto, pode-se concluir que um dos primeiros impactos da indústria de mineração é na geração direta e indireta de empregos beneficiando os mais diversos setores da economia municipal, seja pela geração de renda, seja pela abertura de novos postos de trabalho.

Como ficou demonstrado, para cada posto de trabalho no setor de mineração surgem 13 novas vagas de emprego na sua cadeia produtiva. Assim, por meio da inserção de um fator positivo, a mineração, outros fatores positivos, como aumento na ge- 
ração de empregos, renda e atração de investimentos, surgem de forma sucessiva, em um processo circular e acumulativo, fomentando o desenvolvimento dos municípios.

No que diz respeito à eficiência dos royalties da mineração, é possível afirmar que esse recurso impacta o desenvolvimento dos municípios baianos. Esse impacto, por sua vez, pode ser em maior ou menor magnitude dependendo da estrutura de cada município. Tal estrutura está diretamente associada ao PIB municipal, ao tamanho dessas populações, entre outros fatores que podem ou não potencializar os recursos da CFEM.

Percebeu-se que os municípios maiores possuem fontes diversas de recursos, o que lhes permite não depender unicamente dos repasses de recursos governamentais a fim de fazer frente às suas obrigações com os cidadãos. Aqueles que não contam com uma base econômica diversificada, dependendo em grande parte desses repasses governamentais, como a CFEM, não são eficientes na sua utilização para gerar benefícios à população, visto que esses recursos são utilizados nas obrigações imediatas dos municípios, geralmente em seu custeio e não no que se refere aos investimentos públicos. De maneira oposta, municípios maiores apresentam necessidades diferentes, que são sanadas com uma fonte maior de renda, permitindo que os recursos, no caso, os da CFEM sejam alocados conforme sua finalidade, em sua maioria para a educação.

Percebeu-se, ainda, que os recursos da CFEM geram efeitos positivos sobre a educação dos municípios baianos observados. Foi constatado, também, que a hipótese levantada de que esse recurso favorece o desenvolvimento de tais localidades é verdadeira, pois a alocação desses recursos na área de educação acaba por liberar dotação para outras áreas tidas como prioritárias dentro desses municípios. Isso repercute em melhores indicadores de qualidade de vida (IFDM) e por definição nos seus componentes (IFDM Saúde, IFDM Emprego e Renda) e também na qualidade da educação (IFDM-E).

Assim, entende-se que a maioria dos objetivos propostos neste trabalho, foi evidenciada. Reforça-se a afirmação de que os recursos da CFEM proporcionam benefícios aos municípios recebedores e repercutem em seu desenvolvimento socioeconômico, fato que pode ocorrer em maior ou menor proporção, mas que é recorrente a todos. Contudo, a análise $D E A$, por si só, não possibilita promover interações espaciais entre os municípios observados. Um estudo que trate espacialmente das variáveis permitiria captar o grau de retenção dos benefícios gerados pela CFEM e pelo setor minerador nesses municípios, ou se há um transbordamento às localidades do seu entorno (efeito spillover), o que tende a ser uma etapa complementar a esta pesquisa. 


\section{REFERÊNCIAS}

ADLER, N. F. L.; SINUANY-STERN, Z. Review of ranking methods in the data envelopment analysis context. European Journal of Operational Research, v. 140, p. 249-265, 2002.

ALI, A. I. Streamlined computation for Data Envelopment Analysis, European. Journal of Operational Research, v. 64, p. 61-67, 1993.

ANGULO MEZA, L. et al. ISYDS - Integrated System for Decision Support (SIAD - Sistema Integrado de Apoio à Decisão): A Software Package for Data Envelopment Analysis Model. Pesquisa Operacional, v. 25, i. 3, p. 493-503, 2005.

ANGULO MEZA, L. et al. Seleção de Variáveis em DEA aplicada a uma análise do mercado de energia elétrica. Investigação Operacional, Lisboa, n. 27, p. 21-36, 2007.

ANGULO MEZA, L.; LINS, M. P. E. Review of Methods for Increasing Discrimination in Data Envelopment Analysis. Annals of Operations Research, v. 116, p. 225-242, 2002.

BRASIL. Constituição. República Federativa do Brasil. Brasília, DF: Senado Federal, 1988.

BRASIL. Lei n. 4.425, de 08 de outubro de 1964. Revogada pelo Decreto-Lei n 1.038, de 1969. Disponível em: <http://www.planalto.gov.br/ccivil_03/leis/19501969/L4425.htm>. Acesso em: 18 dez. 2015.

BRASIL. Lei n. 7.990, de 28 de dezembro de 1989. Institui, para os Estados, Distrito Federal e Municípios, compensação financeira pelo resultado da exploração de petróleo ou gás natural, de recursos hídricos para fins de geração de energia elétrica, de recursos minerais em seus respectivos territórios, plataformas continentais, mar territorial ou zona econômica exclusiva, e dá outras providências. (Art. 21, XIX da CF). Diário Oficial da União, Brasília, DF, 29 dez. 1989. Disponível em: <http:// www.planalto.gov.br/ccivil_03/leis/L7990.htm>. Acesso em: 04 ago. 2017.

BRASIL. Lei n. 12.858, de 09 setembro de 2013. Dispõe sobre a destinação para as áreas de educação e saúde de parcela da participação no resultado ou da compensação financeira pela exploração de petróleo e gás natural; altera a Lei n. 7.990, de 28 de dezembro de 1989; e dá outras providências. Diário Oficial da União, Brasília, DF, 10 set. 2013. 
COMPANHIA BAIANA DE PESQUISA MINERAL. 2013. Disponível em: <http:// www.cbpm.com.br/paginas/destaques.php?id=1216>. Acesso em: 10 dez. 2013.

CORREIA, J. S. S. A Bahia é um dos estados mais estudados geologicamente falando do Brasil. Mineração na Bahia, Salvador, p. 2, 2011. Disponível em: <http:// www.google.com.br/url?sa=t\&rct=j\&q=\&esrc=s\&source=web\&cd=2\&ved=0CCMQFjAB\&url=http\%3A\%2F\%2Fwww.redeaplmineral.org.br\%2Fbiblioteca\%2Festudos-e-pesquisas\%2FCADERNO\%2520BAHIA\%2520MINERACaO. pdf\&ei=nucdVL6eLsOSsQTBp4GoCA\&usg=AFQjCNE6vF3hywE9aWqKs2MEj6zW7Uy5jQ\&bvm=bv.75775273,d.cWc. Acesso em: 01 set. 2014.

DALSON FILHO, F. et al. O que fazer e o que não fazer com a regressão: pressupostos e aplicações do modelo linear de Mínimos Quadrados Ordinários (MQO). Revista Política Hoje, v. 20, n. 1, p. 44-99, 2011.

DANIEL, L. P. et. al. Eficiência na oferta de serviços públicos de saúde nos municípios do estado do Mato Grosso. 2011. 82 p. Dissertação (Mestrado em Economia)-Universidade Federal de Viçosa, Viçosa, 2011.

DAVIDSON, R.; MacKINNON, J. G. Estimation and Inference in Econometrics. Oxford: University Press, 1993.

\section{DEPARTAMENTO NACIONAL DE PRODUÇÃO MINERAL. Arrecadação da}

CFEM 2013. 2013. Disponível em: <http://www.dnpm.gov.br/mostra_arquivo.asp?IDBancoArquivoArquivo=8633> . Acesso em: 08 mar. 2014.

\section{DEPARTAMENTO NACIONAL DE PRODUÇÃO MINERAL. Mineração no}

Semiárido Brasileiro. 2009. Disponível em: <http://www.dnpm.gov.br/conteudo. asp?IDSecao=68\&IDPagina=1232> . Acesso em: 30 ago. 2014.

DEPARTAMENTO NACIONAL DE PRODUÇÃO MINERAL. Sobre a CFEM. 2014. Disponível em: <http://www.dnpm.gov.br/conteudo.asp?IDSecao=60>. Acesso em: 06 mar. 2014.

DINIZ NETTO, W.; ANGULO MEZA, L. Análise dos Cursos de Pós-Graduação da CAPES utilizando modelos de Análise Envoltória de Dados - DEA. 076. In: SIMPÓSIO DE PESQUISA OPERACIONAL E LOGÍSTICA DA MARINHA (SPOLM), 18., 2009, Rio de Janeiro. Anais... Rio de Janeiro: SPOLM, 2009. 
EMILIANO, P. C. Fundamentos e Aplicação dos Critérios de Informação: Akaike e Bayesiano. 2009. 92 p. Dissertação (Mestrado em Estatística e Experimentação Agropecuária)-Universidade Federal de Lavras, 2009.

ENRÍQUEZ, M. A. R. S. da. Maldição ou Dádiva? Os dilemas do desenvolvimento sustentável a partir de uma base mineira. 2007. 449 p. Tese (Doutorado em Desenvolvimento Sustentável)-Universidade de Brasília, Brasília, DF, 2007. Disponível em: <http://bdtd.bce.unb.br/tedesimplificado/tde_busca/arquivo. php?codArquivo=2836> . Acesso em: 07 mar. 2014.

ERVILHA, G. T.; ALVES, F. F.; GOMES, A. P. Desenvolvimento municipal e eficiência dos gastos públicos na Bahia: uma análise do IFDM a partir da metodologia DEA. Bahia Análise e Dados, Salvador, v. 23, n. 3, p. 553-585, jul./set. 2013. Disponível em: <http://www.sei.ba.gov.br/images/publicacoes/download/agua/nordeste. pdf $>$. Acesso em: 26 out. 2014.

FEDERAÇÃO DAS INDÚSTRIAS DO ESTADO DO RIO DE JANEIRO. Índice Firjan de Desenvolvimento Municipal - IFDM. Disponível em: <http://www. firjan.com.br/ifdm/>. Acesso em: 18 dez. 2015.

FERNANDES, S. M. de; SANTOS, A. L. M. Contribuição dos recursos minerais e petrolíferos ao desenvolvimento econômico dos municípios baianos. Bahia Análise e Dados, Salvador, v. 24, n. 9, p. 127-140, jan./mar. 2014.

FERREIRA, C. M. C.; GOMES, A. P. Introdução à Análise Envoltória de Dados: Teoria, Modelos e Aplicações. Viçosa: Ed. UFV, 2009.

GOMES, E. G. et al. Fronteira DEA difusa na avaliação de eficiência em agricultura. Investigação Operacional, v. 26, n. 1, p. 65-88, 2006.

GOMES, E. G. Modelos de análise de envoltória de dados com ganhos de soma zero. 2013. Tese (Doutorado em Engenharia de Produção)-Universidade Federal do Rio de Janeiro, Rio de Janeiro, 2013.

GUJARATI, D. Econometria básica. Rio de Janeiro: Elsevier, 2006. 812 p.

HILL, R. C.; GRIFFITHS, W. E.; JUDGE, G. G. Econometria. São Paulo: Saraiva, 2003. $471 \mathrm{p}$.

IBGE. Área Territorial Brasileira. 2014a. Disponível em: <http://www.ibge.gov.br/ home/geociencias/cartografia/default_territ_area.shtm>. Acesso em: 05 mar. 2015. 
IBGE. Classificação Nacional de Atividades Econômicas. Disponível em: < http:// www.cnae.ibge.gov.br/secao.asp?codsecao=B\&TabelaBusca=CNAE_200@ CNAE\%202.0>. Acesso em: 08 dez. 2015.

IBGE. Estados - Bahia. 2014b. Disponível em: <http://www.ibge.gov.br/estadosat/ perfil.php?sigla=ba>. Acesso em: 27 nov. 2015.

INSTITUTO BRASILEIRO DE MINERAÇÃO. Indústria da mineração, ano VI, n. 41, p. 03 fev. 2011. Disponível em: <http://www.ibram.org.br/ sites/1300/1382/00001260.pdf>. Acesso em: 27 fev. 2014.

INSTITUTO BRASILEIRO DE MINERAÇÃO. Informações e análises da economia mineral brasileira. 2012. Disponível em: <http://www.ibram.org.br/ sites/1300/1382/00004430.pdf>. Acesso em 05 mar. 2014.

INSTITUTO NACIONAL DO SEMIÁRIDO. População Total Residente. Disponível em: <http://www.insa.gov.br/censosab/index.php?option=com_content\&view=article\&id=97\&Itemid=96> . Acesso em: 28 ago. 2016.

LETA, F. R. et al. Métodos de melhora de ordenação em DEA aplicados à avaliação estática de tornos mecânicos. Investigação Operacional, v. 25, n. 2, p. 229-242, 2005.

LINS, M. E. et al. O uso da Análise Envoltória de Dados (DEA) para a avaliação de hospitais universitários brasileiros. Ciência e Saúde Coletiva, Rio de Janeiro, v. 12, n. 4, p. 985-998, 2007.

MINISTÉRIO DA FAZENDA. Sistema e Administração tributária - Uma visão Geral. Brasília, DF: Ministério da Fazenda, 2002. Disponível em: <http://www. receita.fazenda.gov.br/Publico/estudotributarios/estatisticas/20SistemaAdministracaoTributaria.pdf>. Acesso em 15 abr. 2014.

MINISTÉRIO DE MINAS E ENERGIA. Marco Regulatório da Mineração. 2013. Disponível em: <http://www.mme.gov.br/mme/menu/Novo_Marco_da_Mineracao. html>. Acesso em: 05 mar. 2014.

MINISTÉRIO DE MINAS E ENERGIA. Relatório Técnico 09: Análise Comparativa de Royalties. 2009. Disponível em: <www.mme.gov.br/.../P03_RT09_Anxlise_Comparativa_de_Royalties.pdf $>$. Acesso em: 30 ago. 2014. 
MONTEIRO, M. A. de. Amazônia: mineração, tributação e desenvolvimento regional. Novos Cadernos NAEA, v. 7, n. 2, p. 159-186, dez. 2004. Disponível em: $<$ http://www.periodicos.ufpa.br/index.php/ncn/article/view/45/40>. Acesso em 06 mar. 2014.

NOGUEIRA, L. C. B.; RAMOS, F. S. Uma proposta de distribuição dos royalties do petróleo introduzindo critérios de eficiência: uma abordagem DEA. TD, João Pessoa: UFPB/PIMES, n. 18, 2013. Disponível em: <http://www.ccsa.ufpb.br/ppge/ arquivos/ensaios/TD18_2013.pdf>. Acesso em: 20 jul. 2014.

REZENDE, A. A.; CORRÊA, C. R.; DANIEL. L. P. Os impactos da política de inovação tecnológica nas universidades federais: uma análise das instituições mineiras. Revista de Economia e Administração, São Paulo, v. 12, n. 1, p. 100131, 2013.

REZENDE, A. C. Bahia vira novo polo de mineração do Brasil. 2011. Disponível em: <http://exame.abril.com.br/brasil/noticias/bahia-vira-novo-polo-de-mineracao-do-brasil>. Acesso em: 29 mar. 2013.

RODRIGUES, A. C. M.; SILVEIRA, S. F. de. R. Análise da eficiência socioeconômica dos municípios mineradores da região central de minas gerais. In: ASSOCIAÇÃO NACIONAL DE PÓS-GRADUAÇÃO E PESQUISA EM ADMINISTRAÇÃO, 33., 2009, São Paulo. Anais... São Paulo, 2009. Disponível em: $<$ http://www.anpad.org.br/diversos/trabalhos/EnANPAD/enanpad_2009/APS/2009_ APS2300.pdf > . Acesso em: 08 mar. 2014.

SECRETARIA DE DESENVOLVIMENTO ECONÔMICO DO ESTADO DA BAHIA. A Bahia em números. 2014. Disponível em: <http://www.sde.ba.gov.br/Pagina.aspx?pagina=abahiaemnumeros $>$. Acesso em: 29 ago. 2016.

SOARES, M. J. C. C. et al. Curso de Análise de Envoltória de Dados. In: SIMPÓSIO BRASILEIRO DE PESQUISA OPERACIONAL, 37., 2005, Gramado. Anais... Gramado: SBPO, 2005. Disponível em: <http://www.uff.br/decisao/sbpo2005_curso. pdf>. Acesso em: 27 out. 2014. 
APÊNDICE A - Scores da Eficiência Composta para os 93 municípios baianos com orientação output (IFDM e IFDM-E) para o período de 2005 a 2011

\begin{tabular}{|c|c|c|c|c|c|c|c|}
\hline Núm. & Municípios & IFDM 2009 & $\begin{array}{c}\text { IFDM-E } \\
2009\end{array}$ & $\begin{array}{c}\text { IFDM } \\
2010\end{array}$ & $\begin{array}{c}\text { IFDM-E } \\
2010\end{array}$ & $\begin{array}{c}\text { IFDM } \\
2011\end{array}$ & $\begin{array}{c}\text { IFDM-E } \\
2011\end{array}$ \\
\hline 1 & Alagoinhas & 0,798 & 0,770 & 0,867 & 0,826 & 0,957 & 0,763 \\
\hline 2 & Alcobaça & 0,566 & 0,739 & 0,518 & 0,702 & 0,790 & 0,651 \\
\hline 3 & Anagé & 0,466 & 0,681 & 0,478 & 0,651 & 0,756 & 0,592 \\
\hline 4 & Andorinha & 0,403 & 0,558 & 0,488 & 0,728 & 0,468 & 0,614 \\
\hline 5 & Barreiras & 0,854 & 0,886 & 0,871 & 0,867 & 0,940 & 0,767 \\
\hline 6 & Barrocas & 0,339 & 0,331 & 0,425 & 0,381 & 0,686 & 0,565 \\
\hline 7 & Boquira & 0,307 & 0,711 & 0,472 & 0,761 & 0,752 & 0,733 \\
\hline 8 & $\begin{array}{l}\text { Brotas de } \\
\text { Macaúbas }\end{array}$ & 0,646 & 0,672 & 0,495 & 0,709 & 0,782 & 0,661 \\
\hline 9 & Brumado & 0,754 & 0,911 & 0,714 & 0,957 & 0,899 & 0,908 \\
\hline 10 & Caculé & 0,642 & 0,898 & 0,728 & 0,904 & 0,900 & 0,878 \\
\hline 11 & Caetité & 0,693 & 0,861 & 0,695 & 0,860 & 0,885 & 0,830 \\
\hline 12 & Camaçari & 0,923 & 0,701 & 0,963 & 0,715 & 1,000 & 0,780 \\
\hline 13 & Camamu & 0,630 & 0,586 & 0,626 & 0,526 & 0,817 & 0,386 \\
\hline 14 & $\begin{array}{l}\text { Campo Alegre } \\
\text { de Lourdes }\end{array}$ & 0,671 & 0,608 & 0,616 & 0,620 & 0,797 & 0,501 \\
\hline 15 & $\begin{array}{l}\text { Campo For- } \\
\text { moso }\end{array}$ & 0,543 & 0,786 & 0,581 & 0,808 & 0,802 & 0,753 \\
\hline 16 & Candeias & 0,909 & 0,777 & 0,939 & 0,757 & 1,000 & 0,773 \\
\hline 17 & Candido Sales & 0,461 & 0,739 & 0,441 & 0,627 & 0,768 & 0,669 \\
\hline 18 & Casa Nova & 0,345 & 0,500 & 0,377 & 0,444 & 0,777 & 0,410 \\
\hline 19 & Caturama & 0,565 & 0,800 & 0,500 & 0,792 & 0,770 & 0,659 \\
\hline 20 & Cordeiros & 0,534 & 0,888 & 0,551 & 0,872 & 0,787 & 0,828 \\
\hline 21 & Coribe & 0,497 & 0,601 & 0,405 & 0,708 & 0,789 & 0,752 \\
\hline 22 & Correntina & 0,746 & 0,780 & 0,721 & 0,784 & 0,881 & 0,743 \\
\hline 23 & Curaçá & 0,507 & 0,843 & 0,418 & 0,807 & 0,600 & 0,710 \\
\hline 24 & Dias D’Ávila & 0,903 & 0,876 & 0,873 & 0,831 & 0,922 & 0,775 \\
\hline 25 & $\begin{array}{l}\text { Euclides da } \\
\text { Cunha }\end{array}$ & 0,496 & 0,618 & 0,494 & 0,571 & 0,803 & 0,589 \\
\hline 26 & Eunápolis & 0,826 & 0,636 & 0,858 & 0,701 & 0,992 & 0,823 \\
\hline 27 & $\begin{array}{l}\text { Feira de San- } \\
\text { tana }\end{array}$ & 0,958 & 0,804 & 0,938 & 0,844 & 0,965 & 0,779 \\
\hline 28 & Guajeru & 0,631 & 0,764 & 0,539 & 0,741 & 0,836 & 0,796 \\
\hline 29 & Guanambi & 0,824 & 0,928 & 0,797 & 0,971 & 0,907 & 0,941 \\
\hline
\end{tabular}




\begin{tabular}{|c|c|c|c|c|c|c|c|}
\hline Núm. & Municípios & IFDM 2009 & $\begin{array}{c}\text { IFDM-E } \\
2009\end{array}$ & $\begin{array}{c}\text { IFDM } \\
2010\end{array}$ & $\begin{array}{c}\text { IFDM-E } \\
2010\end{array}$ & $\begin{array}{c}\text { IFDM } \\
2011\end{array}$ & $\begin{array}{c}\text { IFDM-E } \\
2011\end{array}$ \\
\hline 30 & Guaratinga & 0,710 & 0,707 & 0,745 & 0,728 & 0,925 & 0,831 \\
\hline 31 & Iaçu & 0,629 & 0,703 & 0,724 & 0,715 & 0,835 & 0,641 \\
\hline 32 & Ibiassuçê & 0,691 & 0,827 & 0,686 & 0,766 & 0,837 & 0,691 \\
\hline 33 & Ibicoara & 0,691 & 0,740 & 0,757 & 0,761 & 0,885 & 0,588 \\
\hline 34 & Ibitiara & 0,528 & 0,911 & 0,509 & 0,995 & 0,784 & 0,912 \\
\hline 35 & Ibotirama & 0,668 & 0,708 & 0,733 & 0,894 & 0,854 & 0,777 \\
\hline 36 & Igaporã & 0,670 & 0,805 & 0,658 & 0,904 & 0,862 & 0,846 \\
\hline 37 & Ilhéus & 0,684 & 0,819 & 0,781 & 0,864 & 0,894 & 0,802 \\
\hline 38 & Ipiaú & 0,675 & 0,813 & 0,510 & 0,822 & 0,826 & 0,820 \\
\hline 39 & Ipirá & 0,675 & 0,688 & 0,605 & 0,665 & 0,859 & 0,655 \\
\hline 40 & Ipupiara & 0,782 & 0,924 & 0,796 & 0,904 & 0,864 & 0,819 \\
\hline 41 & Irecê & 0,879 & 1,000 & 0,898 & 1,000 & 0,929 & 0,931 \\
\hline 42 & Itabuna & 0,842 & 0,927 & 0,818 & 0,964 & 0,918 & 0,913 \\
\hline 43 & Itagiba & 0,616 & 0,760 & 0,448 & 0,549 & 0,339 & 0,574 \\
\hline 44 & $\begin{array}{l}\text { Itajú do Co- } \\
\text { lônia }\end{array}$ & 0,443 & 0,532 & 0,338 & 0,453 & 0,744 & 0,462 \\
\hline 45 & Itamaraju & 0,517 & 0,674 & 0,591 & 0,726 & 0,834 & 0,634 \\
\hline 46 & Itapebi & 0,616 & 0,568 & 0,635 & 0,660 & 0,844 & 0,465 \\
\hline 47 & Itapetinga & 0,891 & 0,792 & 0,865 & 0,807 & 0,905 & 0,805 \\
\hline 48 & Itapicuru & 0,308 & 0,525 & 0,322 & 0,543 & 0,757 & 0,450 \\
\hline 49 & Itarantim & 0,550 & 0,435 & 0,544 & 0,426 & 0,795 & 0,386 \\
\hline 50 & Jacaraci & 0,706 & 0,890 & 0,779 & 0,900 & 0,894 & 0,928 \\
\hline 51 & Jacobina & 0,578 & 0,742 & 0,572 & 0,808 & 0,773 & 0,719 \\
\hline 52 & Jaguarari & 0,468 & 0,549 & 0,436 & 0,678 & 0,709 & 0,703 \\
\hline 53 & Jequié & 0,847 & 0,830 & 0,645 & 0,898 & 0,906 & 0,757 \\
\hline 54 & Juazeiro & 0,769 & 0,837 & 0,774 & 0,854 & 0,893 & 0,824 \\
\hline 55 & $\begin{array}{l}\text { Lauro de } \\
\text { Freitas }\end{array}$ & 1,000 & 0,885 & 1,000 & 0,928 & 1,000 & 0,821 \\
\hline 56 & Macajuba & 0,474 & 0,743 & 0,497 & 0,747 & 0,830 & 0,661 \\
\hline 57 & Macarani & 0,569 & 0,891 & 0,561 & 0,903 & 0,809 & 0,921 \\
\hline 58 & $\begin{array}{l}\text { Mata de São } \\
\text { João }\end{array}$ & 0,911 & 0,869 & 0,898 & 0,933 & 0,954 & 1,000 \\
\hline 59 & Matina & 0,679 & 0,875 & 0,612 & 0,864 & 0,859 & 0,937 \\
\hline 60 & $\begin{array}{l}\text { Medeiros } \\
\text { Neto }\end{array}$ & 0,651 & 0,760 & 0,670 & 0,707 & 0,818 & 0,597 \\
\hline
\end{tabular}




\begin{tabular}{|c|c|c|c|c|c|c|c|}
\hline Núm. & Municípios & IFDM 2009 & $\begin{array}{c}\text { IFDM-E } \\
2009\end{array}$ & $\begin{array}{c}\text { IFDM } \\
2010\end{array}$ & $\begin{array}{c}\text { IFDM-E } \\
2010\end{array}$ & $\begin{array}{c}\text { IFDM } \\
2011\end{array}$ & $\begin{array}{c}\text { IFDM-E } \\
2011\end{array}$ \\
\hline 61 & $\begin{array}{l}\text { Miguel Cal- } \\
\text { mon }\end{array}$ & 0,592 & 0,811 & 0,517 & 0,845 & 0,769 & 0,808 \\
\hline 62 & Mirangaba & 0,339 & 0,258 & 0,492 & 0,307 & 0,842 & 0,606 \\
\hline 63 & Mucugê & 0,754 & 0,836 & 0,866 & 0,843 & 0,977 & 0,813 \\
\hline 64 & Mucuri & 0,818 & 0,855 & 0,853 & 0,885 & 0,962 & 0,946 \\
\hline 65 & $\begin{array}{l}\text { Novo Hori- } \\
\text { zonte }\end{array}$ & 0,461 & 0,826 & 0,455 & 0,817 & 0,786 & 0,857 \\
\hline 66 & $\begin{array}{l}\text { Oliveira dos } \\
\text { Brejinhos }\end{array}$ & 0,447 & 0,506 & 0,305 & 0,641 & 0,802 & 0,602 \\
\hline 67 & Ourolândia & 0,566 & 0,683 & 0,566 & 0,635 & 0,806 & 0,575 \\
\hline 68 & Paulo Afonso & 0,927 & 0,943 & 0,895 & 0,944 & 0,991 & 0,937 \\
\hline 69 & Piatã & 0,551 & 0,827 & 0,602 & 0,829 & 0,841 & 0,843 \\
\hline 70 & Pindobaçu & 0,671 & 0,799 & 0,693 & 0,820 & 0,867 & 0,820 \\
\hline 71 & Piripá & 0,677 & 0,684 & 0,687 & 0,761 & 0,500 & 0,688 \\
\hline 72 & Poções & 0,551 & 0,729 & 0,698 & 0,786 & 0,885 & 0,833 \\
\hline 73 & Porto Seguro & 0,972 & 0,781 & 0,964 & 0,793 & 1,000 & 0,861 \\
\hline 74 & Potiraguá & 0,656 & 0,674 & 0,624 & 0,746 & 0,775 & 0,604 \\
\hline 75 & Prado & 0,711 & 0,765 & 0,677 & 0,754 & 0,854 & 0,699 \\
\hline 76 & Ruy Barbosa & 0,462 & 0,787 & 0,500 & 0,797 & 0,781 & 0,763 \\
\hline 77 & Salvador & 0,991 & 0,838 & 0,955 & 0,869 & 0,982 & 0,798 \\
\hline 78 & $\begin{array}{l}\text { Santa Cruz } \\
\text { Cabrália }\end{array}$ & 0,850 & 0,764 & 0,757 & 0,799 & 0,848 & 0,701 \\
\hline 79 & Santa Luzia & 0,277 & 0,450 & 0,306 & 0,404 & 0,766 & 0,393 \\
\hline 80 & $\begin{array}{l}\text { Santa Maria } \\
\text { da Vitória }\end{array}$ & 0,454 & 0,697 & 0,429 & 0,671 & 0,769 & 0,723 \\
\hline 81 & Santa Luz & 0,525 & 0,749 & 0,468 & 0,783 & 0,819 & 0,899 \\
\hline 82 & São Desidério & 0,781 & 0,786 & 0,788 & 0,788 & 0,928 & 0,690 \\
\hline 83 & $\begin{array}{l}\text { São Feliz do } \\
\text { Coribe }\end{array}$ & 0,511 & 0,756 & 0,498 & 0,737 & 0,780 & 0,635 \\
\hline 84 & $\begin{array}{l}\text { São Sebastião } \\
\text { do Passé }\end{array}$ & 0,868 & 0,932 & 0,833 & 0,940 & 0,913 & 0,928 \\
\hline 85 & $\begin{array}{l}\text { Senhor do } \\
\text { Bonfim }\end{array}$ & 0,792 & 0,893 & 0,716 & 0,933 & 0,900 & 0,908 \\
\hline 86 & Sento Sé & 0,458 & 0,665 & 0,406 & 0,681 & 0,800 & 0,671 \\
\hline 87 & Simões Filho & 0,834 & 0,713 & 0,902 & 0,776 & 0,970 & 0,751 \\
\hline 88 & $\begin{array}{l}\text { Teixeira de } \\
\text { Freitas }\end{array}$ & 0,919 & 0,890 & 0,843 & 0,871 & 0,958 & 0,830 \\
\hline 89 & Tucano & 0,454 & 0,664 & 0,538 & 0,708 & 0,818 & 0,778 \\
\hline
\end{tabular}




\begin{tabular}{|r|l|r|r|r|r|r|r|}
\hline Núm. & Municípios & IFDM 2009 & $\begin{array}{c}\text { IFDM-E } \\
\mathbf{2 0 0 9}\end{array}$ & $\begin{array}{c}\text { IFDM } \\
\mathbf{2 0 1 0}\end{array}$ & $\begin{array}{c}\text { IFDM-E } \\
\mathbf{2 0 1 0}\end{array}$ & $\begin{array}{c}\text { IFDM } \\
\mathbf{2 0 1 1}\end{array}$ & $\begin{array}{c}\text { IFDM-E } \\
\mathbf{2 0 1 1}\end{array}$ \\
\hline 90 & Uauá & 0,423 & 0,846 & 0,439 & 0,855 & 0,780 & 0,920 \\
\hline 91 & Valença & 0,707 & 0,694 & 0,730 & 0,679 & 0,879 & 0,684 \\
\hline 92 & Vera Cruz & 0,667 & 0,729 & 0,692 & 0,772 & 0,809 & 0,670 \\
\hline 93 & $\begin{array}{l}\text { Vitória da } \\
\text { Conquista }\end{array}$ & 0,870 & 0,780 & 0,864 & 0,794 & 0,932 & 0,774 \\
\hline
\end{tabular}

Fonte: os autores.

\section{Como citar este artigo:}

\section{ABNT}

CERQUEIRA, Jéssica da Silva; REZENDE, Adriano Alves de; SANTOS, Carlos Eduardo Ribeiro. Os efeitos dos royalties da mineração sobre a promoção do desenvolvimento econômico dos municípios baianos: uma análise do período de 2009 a 2011 por meio da abordagem DEA. RACE, Revista de Administração, Contabilidade e Economia, Joaçaba: Ed. Unoesc, v. 16, n. 2, p. 603-632, maio/ago. 2017. Disponível em: <http://editora.unoesc.edu.br/index.php/race>. Acesso em: dia/mês/ ano.

\section{APA}

Cerqueira, J. da S., Rezende, A. A. de, \& Santos, C. E. R. (2017). Os efeitos dos royalties da mineração sobre a promoção do desenvolvimento econômico dos municípios baianos: uma análise do período de 2009 a 2011 por meio da abordagem DEA. RACE, Revista de Administração, Contabilidade e Economia, 16(2), 603-632. Recuperado em dia/mês/ano, de http://editora.unoesc.edu.br/index.php/race 



\title{
Disponível em:
}

http://editora.unoesc.edu.br/index.php/race

RACE, Joaçaba, v. 16, n. 2, p. 633-654, maio/ago. 2017

\section{PERFORMANCE E FOCO DO GESTOR EM FUNDOS MULTIMERCADOS}

\author{
Performance and managers' focus in multimarket funds
}

\section{Patrycia Olivo Moreira}

E-mail: patrycia_olivo@hotmail.com

Graduada em Ciências Econômicas pela Universidade Federal de Uberlândia; Mestranda em Administração (Gestão Financeira e Controladoria) na Universidade Federal de Uberlândia; Assistente Administrativo na empresa Martins Comércio e Serviços de Distribuição S.A.

Vitor Borges Tavares

E-mail: vitorbtavares@gmail.com Mestre em Administração (Gestão Financeira e Controladoria) pela Universidade Federal de Uberlândia; Graduado em Administração pela Universidade Federal de Uberlândia; Administrador no Instituto Federal do Triângulo Mineiro.

Rodrigo Fernandes Malaquias

E-mail: rodrigofmalaquias@yahoo.com.br Doutor em Administração (Finanças) pela Fundação Getúlio Vargas; Mestre em Administração (Finanças) pela Universidade Federal de Uberlândia; Professor nos Cursos de graduação, mestrado e doutorado em Ciências Contábeis da Faculdade de Ciências Contábeis da Universidade Federal de Uberlândia e no mestrado em Administração da Faculdade de Gestão e Negócios da Universidade Federal de Uberlândia. Endereço para contato: Avenida João Naves de Ávila, 2121, Blocos F e 1F, Salas 1F 215 e 216, Campus Santa Mônica, 38400-902, Uberlândia, Minas Gerais, Brasil.

Artigo recebido em 30 de setembro de 2016. Aceito em 03 de abril de 2017. 


\section{Resumo}

O objetivo principal com este artigo foi analisar a relação entre o foco do gestor e a performance dos fundos de investimentos multimercados. Com base em estudos anteriores, o modelo de pesquisa também considerou o foco da família administradora. A base de dados foi composta por 2.942 fundos no período de janeiro de 2012 a dezembro de 2015. Observou-se que o foco da família de fundos apresentou relação positiva com o desempenho, assim como o foco do gestor em fundos multimercados; porém, essa relação não foi persistente para diferentes medidas de performance como variável dependente. Com base nesses resultados, evidenciaram-se, nesta pesquisa, variáveis que podem ser utilizadas por cotistas de fundos de investimentos para a alocação de seus recursos no mercado financeiro.

Palavras-chave: Investidores institucionais. Gestão ativa. Economia de escala.

\section{Abstract}

The aim of this research is to analyze the relationship between managers' focus and the performance of multimarket investment funds. Grounded in previous research, the quantitative model of this study also involves the focus of funds families. The database is comprised of 2,942 investment funds in the period from january 2012 to december 2015. We observed that both managers' focus and families' focus in the category of multimarket funds have a positive effect on the performance of investment funds. Nevertheless, the positive effect of these variables is not consistent among different indexes of performance. Based on these results, this research discloses some variables that investors can use in order to allocate their financial resources in the capital market.

Keywords: Institutional investors. Active management. Economies of scale.

\section{INTRODUÇÃO}

O mercado de capitais corresponde a uma parte importante da economia de um país. Nesse contexto, segundo Davis (2003), o desenvolvimento dos fundos de investimento influencia o tamanho do mercado de capitais estimulando a economia como um todo. No Brasil, a indústria de fundos de investimentos apresentou considerável crescimento nos últimos anos (GOMES; CRESTO, 2010; MALAQUIAS; EID JUNIOR, 2014).

Tizziani et al. (2010) apontam que houve um aumento da credibilidade do mercado brasileiro em decorrência da estabilização da moeda (Plano Real), do controle da inflação e da dívida externa e das mudanças na legislação que regulam melhor o mercado, tornando-o mais transparente e confiável aos investidores. 
De acordo com a Associação Brasileira das Entidades dos Mercados Financeiros e de Capitais (Anbima) (2015), a indústria de fundos brasileira vem sofrendo transformações ao longo do século XXI. Essas mudanças são refletidas no aumento dos números de cotistas, do seu patrimônio líquido e do volume de fundos disponíveis. Em 2014, havia 121 gestoras associadas à Anbima com um total de R \$ 2,7 trilhões em patrimônio líquido, distribuídos em 14 mil fundos formados por 11,5 milhões de cotistas e captação de 2,2 bilhões no mercado doméstico, sendo a sétima maior indústria de gestão de recursos do mundo. Em junho de 2009 eram 4.606 fundos geridos por 81 administradoras (IQUIAPAZA, 2009). Houve, portanto, um aumento de 49,38\% do número de administradoras entre junho de 2009 e dezembro de 2014 e, um aumento superior a $200 \%$ do total de fundos no mesmo período.

No mercado acionário, de acordo com a Hipótese de Eficiência de Mercado (HEM), os preços dos títulos refletem todas as informações relevantes disponíveis sobre ele (FAMA, 1970). Em sua forma semiforte, não há (elevada) possibilidade ganhos de arbitragem, pois as informações públicas disponíveis são refletidas no preço das ações, portanto, as possíveis chances de auferir lucros extraordinários com base nessas informações são pequenas. Essa teoria e esses argumentos mostraram-se aderentes em países com mercados de capitais mais avançados, como Suíça e Estados Unidos, onde há um sistema financeiro e um mercado de capitais eficientes (ACKERMANN; MCENALLY; RAVENSCRAFT, 1999; AMIN; KAT, 2003).

Contudo, cabe o questionamento dessa teoria para mercados emergentes, em que a velocidade do ajuste de preços dos títulos sobre certa informação lançada pode ser mais lenta em comparação a mercados desenvolvidos (MALAQUIAS, 2012), corroborando sobre a precificação de ativos no mercado brasileiro (CAMARGOS; ROMERO, 2006; ROCHMAN; EID JUNIOR, 2007).

A eficiência de alocação de recursos e o desenvolvimento dos mercados de capitais podem ser influenciados por ações governamentais (BENCIVENGA; SMITH, 1991) e também pelo grau de assimetria de informação (EID JUNIOR; SECURATO, 2010). Dessa forma, corrobora-se a possibilidade de que é possível agregar valor no mercado brasileiro com base na gestão ativa, por conta de seu nível de eficiência informacional.

Nesse contexto de possível agregação de valor, Siggelkow (2003) verificou que os fundos mútuos que pertencem a famílias mais especializadas têm resultados melhores do que fundos similares de famílias diversificadas, o que foi ratificado por Iquiapaza (2009).

Na relação entre famílias de fundos e investidores há um intermediário, o gestor do fundo de investimento, que desempenha um papel crucial para o desempenho do 
fundo. A importância do gestor do fundo é destacada por Bryant (2012), afirmando que, ao comprar um patrimônio do fundo de investimento, o investidor está comprando a perícia de um gerente em escolher ações. Assim como as famílias de fundos, os gestores podem ser mais ou menos especializados em determinados tipos de fundos de investimento. Bryant (2012) verificou que a utilização de um gestor em mais de um fundo de investimento gera um ganho de economia de escala à família de fundo.

Assim, neste trabalho teve-se o seguinte problema de pesquisa: qual a relação entre o foco do gestor e a performance dos fundos de investimento brasileiros? Dessa forma, no trabalho teve-se como objetivo analisar a relação entre o foco do gestor e o desempenho dos fundos de investimentos brasileiros. Ademais, pretendeu-se analisar a relação entre o foco das famílias de fundos e a performance destes.

A justificativa para a realização desta pesquisa se encontra no crescimento do volume de fundos mútuos brasileiros nos últimos anos, na importância da administração mais especializada e focada dos fundos mútuos para agregar valor aos títulos e na influência sobre o desenvolvimento de mercado de capitais e o progresso da economia. Estudos específicos que envolvem simultaneamente o foco do gestor, o foco das famílias e a performance dos fundos administrados não foram identificados, até o que se pôde pesquisar sobre o assunto.

Além disso, a escolha do Brasil como objeto de estudo se justifica pelo fato de o nosso País ser o maior economicamente entre os países da América Latina. Atualmente, o Brasil é o único país latino-americano entre os 10 mais ricos do mundo, ocupando o sétimo lugar (INTERNATIONAL MONETARY FUND, 2015). Além disso, segundo a Associação Brasileira das Entidades dos Mercados Financeiros e de Capitais (2015), o Brasil também é a sétima maior indústria de fundos do mundo, sendo a maior entre os países da América Latina. Não obstante, nas últimas décadas, sofreu mudanças econômicas positivas que possibilitaram forte crescimento econômico, estabilidade macroeconômica e bom grau de investimento, tornando-o um concorrente em nível mundial (BLACK; CARVALHO; SAMPAIO, 2014).

\section{REFERENCIAL TEÓRICO}

\subsection{HIPÓTESE DE EFICIÊNCIA DE MERCADO}

O mercado de capitais tem como propósito transferir fundos entre os credores, os quais são os poupadores de dinheiro, e os devedores, os tomadores de dinhei- 
ro, de forma eficiente (COPELAND; WESTON; SHASTRI,2005). Segundo Fama (1970), a base do desenvolvimento de um país são os mercados de capitais, e a capacidade do mercado de alocar poupança e investimento pode influenciar a precificação dos títulos.

Considerada base da Moderna Teoria de Finanças, a Hipótese de Eficiência de Mercado (HEM), desenvolvida por Fama (1970), tem como base a afirmativa de que o preço dos ativos de uma companhia reflete as informações disponíveis sobre essa empresa no mercado. Desse modo, os investidores não conseguiriam auferir consistentemente retornos superiores ao risco enfrentado para cada ativo, com base em negociações realizadas de acordo com o nível informacional no qual o mercado venha a se classificar. Nesse contexto, o mercado de capitais é considerado eficiente quando seus ativos financeiros refletem todas as informações disponíveis sobre ele no mercado.

Com base no comportamento dos mercados financeiros, Fama (1970) propôs três formas de eficiência: forte, semiforte e fraca. A hipótese da forma fraca de eficiência do mercado estabelece que o preço dos ativos reflete toda a informação histórica relevante. A hipótese de eficiência sobre a forma semiforte determina que os preços dos ativos espelham toda a informação pública disponível no mercado. A hipótese de eficiência em sua forma forte afirma que os preços das ações refletem integralmente todas as informações existentes no mercado, sendo estas públicas ou privadas. Qualquer informação que possa ter vínculo com a ação será incorporada no valor dessa ação (FAMA, 1970; FAMA, 1991), o que pode originar as anomalias temporárias de mercado.

Porém, no que diz respeito ao comportamento dos fundos de investimentos em relação à HEM, por um lado, a gestão passiva dos fundos converge com a HEM, por outro, a gestão ativa dos fundos em que os gestores ativos tentam superar o índice de benchmark do mercado diverge da HEM. A gestão ativa dos fundos consiste na concepção de que alguns gestores apresentam habilidades gerenciais diferenciadas, permitindo-os a identificação de ativos inadequadamente precificados e, com isso, a obtenção de retornos superiores (BOLLEN; BUSSE, 2005).

Em consonância com o exposto de que os fundos podem obter ganhos não nulos, a assimetria de informação ocorre quando algum agente possui informações de uma empresa, informações que não estão disponíveis para os outros agentes (HEALY; PALEPU, 1993). Nesse contexto, Abad e Rubia (2005) afirmam que existem dois tipos de investidores: os agentes informados, que dispõem de informações privadas usando-as para obter ganhos econômicos enquanto o preço do ativo não reflete seu valor fundamental, e os agentes desinformados, que detêm somente as informações publicamente disponíveis. 
A assimetria de informação possibilita o surgimento de conflitos de interesses baseado na teoria de agência (JENSEN; MECKLING, 1976). Isso ocorre em razão de o gestor dos fundos poder fazer uso de informação privilegiada em benefício próprio, obtida em decorrência da assimetria de informação.

A assimetria informacional decorre da obtenção de informação relevante que ainda não está disponível ao público em geral, mas que pode ser obtida por investidores que têm acesso a ela. Esse privilégio na obtenção da informação impõe um risco informacional aos participantes não informados do mercado. Nesse contexto, o ganho dos investidores informados corresponde à perda dos não informados, o que fará com que estes demandem maiores retornos exante, a fim de se resguardarem do risco. Dessa forma, a assimetria de informação gera o aumento exante do custo de capital na emissão de ações no mercado (BRESSAN et al., 2007; LANZANA, 2004).

Nesse contexto, Bressan et al. (2007) desenvolveram um trabalho com a hipótese de que, por reduzir assimetria de informação, a governança corporativa teria relação positiva com a rentabilidade das ações. Eles verificaram que as empresas que possuíam menor assimetria de informação (representada pela proxy governança corporativa) obtiveram rentabilidade média maior do que as que tinham maior assimetria de informação, não rejeitando, dessa forma, a hipótese do estudo.

\subsection{FUNDOS DE INVESTIMENTOS, GESTORES E FAMÍLIAS DE FUNDOS}

Segundo Iquiapaza (2009), os fundos de investimentos correspondem a fundos que captam recursos financeiros de diversos poupadores pequenos, aplicando-os em portfólios diversificados, como, por exemplo: ações, debêntures, bônus, entre outros. Esses fundos proporcionam certas vantagens aos seus investidores quando comparados a investidores individuais, como maior liquidez, diversificação de portfólio e diminuição de custos por causa da economia de escala. Oliveira Filho (2008) enxerga a diversificação como um dos benefícios dos fundos de investimento. Outrossim, a Teoria do Portfólio, desenvolvida por Markowitz (1952), define a diversificação como uma forma de otimizar o desempenho dos investimentos.

Há estudos sobre conflitos de interesse em fundos de investimento (ZENG, YUAN e ZHANG, 2015), os efeitos de suas negociações e fluxos financeiros no preço das ações do mercado de capitais (JIAO; YE, 2014; NARAYAN; NARAYAN; PRABHEESH, 2014), bem como a associação da composição de suas carteiras com o gerenciamento de resultados das companhias investidas (CHI, YANG; YOUNG, 2014). 
As características relacionadas aos fundos de investimentos também despertam interesse dos pesquisadores, como é o caso da análise de efeitos do tamanho dos fundos, da estrutura de gestão e, no caso desta pesquisa, da família e do respectivo gestor. As famílias de fundos correspondem a conjuntos de fundos com diferentes tipos de exposição de riscos e diferentes perfis de retornos, administrados por uma mesma empresa ou empresas de um mesmo grupo, e o seu foco está relacionado com o grau de especialização destas com a presença, mais ou menos focada, em determinadas categorias de investimentos (IQUIAPAZA, 2009).

A grande variedade de fundos oferecida por uma família pode fazer os investidores se restringirem a ela (KEMPF; RUENZI, 2008). Assim, para Massa (1998), a diversificação de tipos de fundos pode ser utilizada como uma estratégia de marketing para atender à heterogeneidade dos investidores.

Entretanto, Siggelkow (2003) afirma que os fundos mútuos que pertencem a famílias mais especializadas têm resultados melhores do que fundos similares, mas administrados por famílias diversificadas. A administradora mais focada tende a possuir maior habilidade para desenvolver competências e economias de escala ao investir, atingindo maior participação de mercado e desempenho superior, pois as famílias que se especializam têm melhores condições de avaliar e atrair os gestores de fundos em seu segmento específico. Nessa linha, Ciccotello, Miles e Walsh (2006) apontam que as famílias que se especializam dentro de uma pequena linha de produtos podem proporcionar maiores retornos líquidos do que as famílias não focadas. Isso ocorre em razão das economias de escopo e também do conhecimento desenvolvido por essa família especializada.

Segundo Bryant (2012), cada objetivo de investimento requer que o gestor do fundo tenha específico conhecimento, experiência e nível de competência. Fundos com ativos de características diferentes requerem diferentes habilidades de gerenciamento (DELI, 2002). Um gerente que segue uma estratégia de negociação consistente e que proporciona retornos consistentes ao longo de um período relativamente longo de tempo beneficia os investidores, diminuindo a volatilidade dos retornos a eles proporcionados (BUSSE, 1999).

Conforme dados da Associação Brasileira das Entidades dos Mercados Financeiro e de Capitais (2015), a CVM editou, no final de 2014, as Instruções ns. 554 e 555 com a finalidade de atualizar as formas de divulgação de informações por parte dos fundos de investimento, redefinindo conceitos de investidores. Com vigência desde 01 de julho de 2015, as normas pretendem aumentar a eficiência da indústria, reduzindo custos e aumentando a transparência das informações ao público. Nesse 
contexto, houve a classificação de fundos pela CVM, reduzindo-os de sete para quatro classes de fundos de investimentos nacionais.

De acordo com Malaquias e Eid Junior (2013), um segmento de fundos que vem sendo pesquisado recentemente em nível internacional se refere aos hedge funds. No Brasil, os que mais se aproximam desses fundos dizem respeito aos fundos multimercados (JOAQUIM; MOURA, 2011). Especificidades desses fundos, como relação da performance com a teoria de agência (CHEVALIER; ELISSON, 1997; ACKERMANN; MCENALLY; RAVENSCRAFT, 1999; AGARWAL; NAIK, 2000), HEM, operações com derivativos, pagamento de taxas de performance e admissão de posição de alavancagem fazem com que esse tipo de fundo seja objeto de estudo dos pesquisadores (AGARWAL; NAIK, 2000; LI; ZHANG; ZHAO, 2011).

Os fundos multimercados registraram as maiores rentabilidades entre os tipos classificados (ASSOCIAÇÃO BRASILEIRA DAS ENTIDADES DOS MERCADOS FINANCEIRO E DE CAPITAIS, 2015). A taxa subiu de 6,73\% em 2013 para 10,81\% em 2014. Nesse contexto, os fundos abordados neste trabalho são fundos multimercados que captam investimentos em ativos de diversos mercados, como de ações, renda fixa, renda variável, em diversas proporções.

No processo de investimento em fundos, a companhia administradora contrata um gestor que irá prestar serviços às famílias de fundos. Assim, a organização das famílias de fundo de investimento pode envolver três atores: famílias de fundos, gestores de fundos e investidores.

A importância do gestor pode ser percebida nos resultados obtidos no trabalho de Clare et al. (2014). Eles verificaram que a substituição de um gestor de fundo com desempenho médio tende a melhorar os resultados do fundo, e que a substituição do gestor de um fundo com alto desempenho tende a piorar o desempenho. Ou seja, o gestor do fundo desempenha um papel relevante na família de fundos para a obtenção de bons resultados.

Alguns estudos verificaram que há uma relação negativa entre a quantidade de fundos administrada pelo gestor e o desempenho dos fundos (PRATHER; BERTIN; HENKER, 2004; HU; CHANG, 2008; HU; YU; WANG, 2012). Entretanto, até o que se pôde analisar, não se tem conhecimento de trabalhos que analisaram se a especialização do gestor, ou seja, o foco em determinada categoria de fundo de investimento tem relação com o desempenho dos fundos.

Dessa forma, em consonância com a aceitação da não ocorrência da HEM e de que há ganhos não nulos com os resultados encontrados para a relação entre o foco das famílias e a performance dos fundos de investimento e, ainda, fazendo uma 
analogia entre o foco da família e o foco do gestor do fundo, neste trabalho têm-se as seguintes hipóteses:

$H_{1}$ : O foco do gestor apresenta relação positiva com a performance dos fundos de investimento;

$H_{2}$ : O foco da família dos fundos apresenta relação positiva com a performance dos fundos de investimento.

\section{METODOLOGIA}

Para análise neste estudo os dados foram coletados do Sistema de Informações da Associação Brasileira das Entidades dos Mercados Financeiro e de Capitais (SI-Anbima) bem como do Banco de Dados Economatica, no período de janeiro de 2012 a dezembro de 2015. A junção das bases de dados do SI-Anbima com as informações disponíveis no sítio eletrônico da CVM, após a exclusão dos missing values, resultou em 2.942 fundos de investimentos multimercados com dados disponíveis para a realização do estudo.

A variável rentabilidade corresponde à variação de quanto o fundo rendeu no período t em relação ao período t-1, apresentada mensalmente. Essa variável foi submetida ao procedimento de winsorização a 1\% para eliminar potenciais vieses decorrentes de outliers. A rentabilidade mensal serviu de base para o cálculo da variável dependente do modelo, o Índice de Sharpe. Assim, no modelo de regressão múltipla, utilizou-se como variável dependente (de saída) o Índice de Sharpe de cada fundo para o período, que pondera o retorno adicional médio do fundo pela sua volatilidade. Considerou-se como estimativa para a taxa livre de risco a taxa Selic mensal, sendo o Índice de Sharpe também submetido ao procedimento de winsorização a $1 \%$.

Observando o estudo de Israelsen (2005), em que fundos com prêmio pelo risco negativo proporcionariam um resultado com viés para o Índice de Sharpe convencional, inseriram-se mais duas variáveis dependentes no estudo: uma (Índice de Sharpe positivo) que considera apenas fundos com Índice de Sharpe positivo e outra (Índice de Sharpe ajustado) que considera o Índice de Sharpe ajustado, conforme proposto por Israelsen (2005). Nesse último caso, quando os fundos possuem prêmio pelo risco positivo, faz-se a ponderação desse valor pela sua volatilidade; contudo, quando o prêmio pelo risco é negativo, eleva-se a volatilidade ao valor de 1 negativo, proporcionando, assim, a sua multiplicação pelo prêmio negativo. Essa seria uma alternativa para melhor classificar fundos de investimento com base no retorno ajustado ao risco. 
Como variáveis de interesse nos testes quantitativos, foram considerados o foco do gestor da família de fundos (FocGest) e o foco da família de fundos (FocFam). Além dessas variáveis, o modelo quantitativo também considera como variáveis de controle o tamanho da família, o tamanho do fundo, a taxa máxima de administração cobrada anualmente e a idade do fundo, além das variáveis dummies taxa de performance do fundo e fundos de investimentos em cotas de fundos de investimentos. A Equação 1 ilustra o modelo quantitativo testado e a descrição das variáveis encontra-se a seguir.

$$
\begin{aligned}
& \text { Sharpe }_{\mathrm{i}}=\beta_{0}+\beta_{1} * \text { TamFundo }_{\mathrm{i}}+\beta_{2} * \text { Idade }_{\mathrm{i}}+\beta_{3} * \text { TxAdm }_{\mathrm{i}}+\beta_{4} * \text { TxPerf }_{\mathrm{i}}+\beta_{5} \\
& * \text { FIC }_{\mathrm{i}}+ \beta_{6} * \text { FocGest }_{\mathrm{i}}+ \\
&+\beta_{7} * \text { FocFam }_{\mathrm{i}}+\beta_{8} * \text { TamFam }_{\mathrm{i}}+\varepsilon_{\mathrm{i}}
\end{aligned}
$$

Em que: Sharpe ${ }_{\mathrm{i}}=$ Índice de Sharpe de cada fundo para o período de análise;

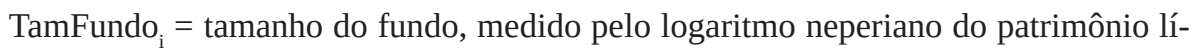
quido médio do fundo no período; Idade $_{i}=$ idade do fundo (em anos) em 31/12/2015; TxAdm $_{\mathrm{i}}=$ taxa máxima de administração cobrada anualmente pelos fundos; TxPerf $_{\mathrm{i}}=$ variável dummy, recebendo valor 1 para fundos que cobram taxa de performance, e 0 para os demais; FIC $_{\mathrm{i}}=$ variável dummy, recebendo valor 1 para fundo de investimento

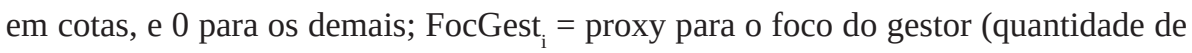
fundos multimercados em relação à quantidade de fundos total sob gestão); FocFam = proxy para o foco da família (quantidade de fundos multimercados em relação à quantidade de fundos da família); TamFam ${ }_{\mathrm{i}}=$ proxy para o tamanho da família, mensurada pelo logaritmo neperiano da quantidade de fundos administrada pela família; $\varepsilon_{\mathrm{i}}$ = termo de erro; $\beta_{0}, \beta_{1}, \beta_{2}, \beta_{3}, \beta_{4}, \beta_{5}, \beta_{6}, \beta_{7}$, e $\beta_{8}=$ parâmetros do modelo.

O foco do gestor (FocGest) foi estimado pela divisão da quantidade de fundos multimercados administrados pelo gestor pela quantidade total de fundos sob responsabilidade do respectivo gestor. De forma semelhante, o foco da família de fundos (FocFam) foi estimado pela divisão da quantidade de fundos multimercados pela quantidade total de fundos sob responsabilidade da respectiva administradora.

O tamanho da família (TamFam) foi medido pelo logaritmo neperiano da quantidade de fundos que a família possui. Essa variável foi utilizada como variável de controle nos trabalhos de Iquiapaza (2009) e Bryant (2012). Em decorrência da possibilidade de fundos maiores terem desempenho superior em relação aos menores em razão do maior poder de barganha e da economia em escala (ROCHMAN; EID JUNIOR, 2006), o tamanho dos fundos (TamFundo) também foi utilizado como uma variável de controle, mensurado por meio do logaritmo neperiano do patrimônio líquido médio de cada fundo no período. 
A variável idade do fundo (Idade) inserida para ponderar os resultados em virtude da possibilidade de desempenho inferior dos fundos decorrente de custos mais altos no início de sua existência (ROCHMAN; EID JUNIOR, 2006), está representada em anos, indicando a idade do fundo na data de 31 de dezembro de 2015. Em trabalhos que analisaram a relação dessa variável com a rentabilidade dos fundos, Dangl et al. (2008) e Li et al. (2011) verificaram uma relação negativa entre ela e a rentabilidade.

A variável taxa de administração (TxAdm) tem por objetivo captar as variações da performance decorrentes de fundos que cobram maiores e menores taxas. Segundo Iquiapaza (2009), por meio dessa taxa a família de fundos tenta maximizar o seu benefício, otimizando os ativos sob sua administração. Além desse autor, Bryant (2012) também utilizou essa variável como controle. Outra taxa estabelecida foi a de performance (TxPerf), cujo pagamento aos gestores varia de acordo com o desempenho do fundo. Elton, Gruber e Blake (2003) a definem como a recompensa pelo excesso de desempenho que um fundo obtém em comparação com seu benchmark.

Foi incluída no modelo a variável dummy FIC, que diferencia os fundos de investimento em cotas dos demais. De acordo com Amin e Kat (2003), os fundos de investimento em cotas podem gerar duplicidade na cobrança de taxas e, assim, prejudicar a performance dos fundos. Em razão disso, Malaquias (2012) também utilizou essa variável em seu estudo. O Quadro 1, a seguir, resume as variáveis utilizadas neste estudo.

Quadro 1 - Variáveis independentes utilizadas no estudo

\begin{tabular}{|l|l|l|}
\hline \multicolumn{1}{|c|}{ Variável } & \multicolumn{1}{|c|}{ Descrição } & \multicolumn{1}{c|}{ Forma de medida } \\
\hline TamFundo & Tamanho do fundo & $\begin{array}{l}\text { Logaritmo neperiano do patrimônio líquido médio do fundo } \\
\text { no período. }\end{array}$ \\
\hline Idade & Idade do fundo & Idade do fundo, em anos, em 31/12/2015. \\
\hline TxAdm & Taxa de administração & $\begin{array}{l}\text { Taxa máxima de administração cobrada anualmente pelo } \\
\text { fundo. }\end{array}$ \\
\hline TxPerf & Taxa de performance & $\begin{array}{l}\text { Variável dummy: assume 1 para fundos que cobram taxa de } \\
\text { performance e zero para os demais. }\end{array}$ \\
\hline FIC & Fundos de inv. em cotas & $\begin{array}{l}\text { Variável dummy: assume 1 para fundos de cotas e zero para } \\
\text { os demais. }\end{array}$ \\
\hline FocGest & Foco do gestor & $\begin{array}{l}\text { Divisão da quantidade de fundos multimercados do gestor } \\
\text { pela quantidade total de fundos sob responsabilidade do } \\
\text { respectivo gestor. }\end{array}$ \\
\hline FocFam & Foco da família & $\begin{array}{l}\text { Divisão da quantidade de fundos multimercados pela quan- } \\
\text { tidade total de fundos sob responsabilidade da respectiva } \\
\text { administradora. }\end{array}$ \\
\hline TamFam & Tamanho da família & $\begin{array}{l}\text { Logaritmo neperiano da quantidade de fundos que a família } \\
\text { possui. }\end{array}$ \\
\hline Fonte: os autores.
\end{tabular}




\section{RESULTADOS}

A Tabela 1 apresenta a estatística descritiva das variáveis utilizadas no trabalho. Ela mostra o número de observações de cada variável, bem como os valores mínimo, médio e máximo de cada uma, além do desvio padrão.

Tabela 1 - Estatística descritiva das variáveis utilizadas no trabalho

\begin{tabular}{lrrrrr}
\hline \multicolumn{1}{c}{ Variáveis } & n & \multicolumn{1}{c}{ Média } & Desv. Pad. & \multicolumn{1}{c}{ Mín. } & \multicolumn{1}{c}{ Máx. } \\
\hline Índ. Sharpe & 2.942 & 0,005 & 0,430 & $-9,513$ & 1,902 \\
$\begin{array}{l}\text { Índ. Sharpe } \\
\text { (positivo) }\end{array}$ & 1.556 & 0,211 & 0,274 & 0,001 & 1,902 \\
$\begin{array}{l}\text { Índ. Sharpe } \\
\text { (ajustado) }\end{array}$ & 2.942 & $-0,068$ & 0,690 & $-5,290$ & 1,902 \\
TamFundo & & & & & \\
Idade & 2.942 & 17,587 & 1,487 & 12,608 & 23,294 \\
TxAdm & 2.942 & 8,538 & 3,700 & 4,064 & 22,992 \\
TxPerf & 2.942 & 0,760 & 1,012 & 0,000 & 10,000 \\
FIC & 2.942 & 0,195 & 0,397 & 0,000 & 1,000 \\
FocGest & 2.942 & 0,475 & 0,499 & 0,000 & 1,000 \\
FocFam & 2.942 & 73,811 & 23,935 & 3,846 & 100,000 \\
TamFam & 2.942 & 66,329 & 14,948 & 3,846 & 100,000 \\
\hline
\end{tabular}

Fonte: os autores.

Nota: Î́nd. Sharpe = Índice de Sharpe de cada fundo para o período de análise; Índ. Sharpe (positivo) = Índice de Sharpe de cada fundo para o período de análise (fundos com Índice de Sharpe negativo foram excluídos para essa variável); Índ. Sharpe (ajustado) = Índice de Sharpe ajustado, conforme proposto por Israelsen (2005), de cada fundo para o período de análise; TamFundo = tamanho do fundo, medido pelo logaritmo neperiano do patrimônio líquido médio do fundo no período; Idade = idade do fundo (em anos) em 31/12/2015; TxAdm = taxa máxima de administração cobrada anualmente pelos fundos; TxPerf = variável dummy, recebendo valor 1 para fundos que cobram taxa de performance, e 0 para os demais; FIC = variável dummy, recebendo valor 1 para fundo de investimento em cotas, e 0 para os demais; FocGest = proxy para o foco do gestor; FocFam = proxy para o foco da família; TamFam = proxy para o tamanho da família, mensurada pelo logaritmo neperiano da quantidade de fundos administrada pela família.

Os resultados da Tabela 1 mostram que a taxa média de administração (variável TxAdm) cobrada pelos fundos da amostra é de 0,76\% ao ano, e que 19,5\% dos fundos multimercados da amostra cobram taxa de performance (variável TxPerf). Ademais, pode-se notar que 47,5\% dos fundos são fundos de investimentos em cotas (variável FIC). Após a verificação da estatística descritiva das variáveis, apresentam-se as Tabelas 2 e 3, que contêm as estimativas para o modelo de regressão desenvolvido. Por meio dessas Tabelas é possível avaliar o resultado para o teste das hipóteses apresentadas no referencial teórico. 
Tabela 2 - Resultados da análise de regressão (Variáveis dependentes: Índ. Sharpe e Índ. Sharpe positivo)

\begin{tabular}{|c|c|c|c|c|c|c|}
\hline \multirow{3}{*}{$\begin{array}{l}\text { Variáveis } \\
\text { TamFun- } \\
\text { do }\end{array}$} & \multicolumn{6}{|c|}{ Índ. Sharpe } \\
\hline & \multicolumn{2}{|c|}{ Mod. 01} & \multicolumn{2}{|c|}{ Mod. 02} & \multicolumn{2}{|c|}{ Mod. 03} \\
\hline & 0,0522 & $* * *$ & 0,0530 & $* * *$ & 0,0506 & $* * *$ \\
\hline Idade & $-0,0039$ & $*$ & $-0,0043$ & $* *$ & $-0,0040$ & ** \\
\hline TxAdm & $-0,0221$ & $* * *$ & $-0,0233$ & $* * *$ & $-0,0224$ & $* * *$ \\
\hline TxPerf & $-0,0026$ & & $-0,0014$ & & $-0,0053$ & \\
\hline FIC & 0,0038 & & 0,0038 & & 0,0029 & \\
\hline FocGest & 0,0007 & & 0,0017 & $* * *$ & & \\
\hline FocFam & 0,0024 & $* * *$ & & & 0,0031 & $* * *$ \\
\hline TamFam & 0,0160 & $*$ & 0,0193 & $* *$ & 0,0181 & $* *$ \\
\hline Constante & $-1,1879$ & $* * *$ & $-1,1308$ & $* * *$ & $-1,1631$ & $* * *$ \\
\hline$n$ & & & 2.942 & & & \\
\hline
\end{tabular}

Fonte: os autores.

\begin{tabular}{|c|c|c|c|c|c|}
\hline \multicolumn{6}{|c|}{ Índ. Sharpe (Pos) } \\
\hline \multicolumn{2}{|c|}{ Mod. 01} & \multicolumn{2}{|c|}{ Mod. 02} & \multicolumn{2}{|c|}{ Mod. 03} \\
\hline 0,0224 & $* * *$ & 0,0224 & $* * *$ & 0,0273 & $* * *$ \\
\hline$-0,0030$ & & $-0,0034$ & & $-0,0032$ & \\
\hline$-0,0231$ & $* * *$ & $-0,0236$ & $* * *$ & $-0,0263$ & $* * *$ \\
\hline 0,0282 & & 0,0263 & & 0,0401 & \\
\hline$-0,0057$ & & $-0,0050$ & & $-0,0085$ & \\
\hline$-0,0023$ & $* * *$ & $-0,0016$ & $* * *$ & & \\
\hline 0,0018 & ** & & & 0,0000 & \\
\hline 0,0060 & & 0,0089 & & $-0,0031$ & \\
\hline$-0,1351$ & & $-0,0816$ & & $-0,2039$ & \\
\hline
\end{tabular}

Tabela 3 - Resultados da análise de regressão (Variável dependente: Índice de Sharpe ajustado)

\begin{tabular}{|c|c|c|c|c|c|c|}
\hline \multirow[b]{3}{*}{ TamFundo } & \multicolumn{6}{|c|}{ Índ. Sharpe (Ajust.) } \\
\hline & \multicolumn{2}{|c|}{ Mod. 01} & \multicolumn{2}{|c|}{ Mod. 02} & \multicolumn{2}{|c|}{ Mod. 03} \\
\hline & 0,0497 & $* * *$ & 0,0503 & $* * *$ & 0,0520 & $* * *$ \\
\hline Idade & 0,0102 & $* * *$ & 0,0098 & $* * *$ & 0,0104 & $* * *$ \\
\hline TxAdm & $-0,0661$ & $* * *$ & $-0,0672$ & $* * *$ & $-0,0657$ & $* * *$ \\
\hline TxPerf & $-0,0109$ & & $-0,0099$ & & $-0,0072$ & \\
\hline FIC & 0,1362 & $* * *$ & 0,1363 & $* * *$ & 0,1374 & $* * *$ \\
\hline FocGest & $-0,0010$ & & $-0,0002$ & & & \\
\hline FocFam & 0,0021 & & & & 0,0011 & \\
\hline TamFam & 0,0682 & $* *$ & 0,0710 & $* *$ & 0,0654 & $* *$ \\
\hline Constante & $-1,5677$ & $* * *$ & $-1,5188$ & $* * *$ & $-1,6015$ & $* * *$ \\
\hline$n$ & & & 2.94 & & & \\
\hline
\end{tabular}

Fonte: os autores.

Nota para as Tabelas 2 e 3: Índ. Sharpe = Índice de Sharpe de cada fundo para o período de análise; Índ. Sharpe (positivo) = Índice de Sharpe de cada fundo para o período de análise (fundos com Índice de Sharpe negativo foram excluídos para essa variável); Índ. Sharpe (ajustado) = Índice de Sharpe ajustado, conforme proposto por Israelsen (2005), de cada fundo para o período de análise; TamFundo = tamanho do fundo, medido pelo logaritmo neperiano do patrimônio líquido médio do fundo no período; Idade = idade do fundo (em anos) em 31/12/2015; TxAdm = taxa máxima de administração cobrada anualmente pelos fundos; TxPerf = variável dummy, recebendo valor 1 para fundos que cobram taxa de performance, e 0 para os demais; FIC = variável dummy, recebendo valor 1 para fundo de investimento em cotas, e 0 para os demais; FocGest = proxy para o foco do gestor; FocFam = proxy para o foco da família; TamFam = proxy para o tamanho da família, mensurada pelo logaritmo neperiano da quantidade de fundos administrada pela família. $* * *=$ significativo a $1 \%$; $* *=$ significativo a $5 \%$; $*$ = significativo a $10 \%$. Estatística Variance Inflation Factor (VIF): abaixo de 2 para todas as variáveis independentes. Os níveis de significância consideram erros padrão robustos à heterocedasticidade.

Com o objetivo de evitar problemas com heterocedasticidade foram considerados erros padrão robustos para a estimativa dos parâmetros. No que se refere à 
multicolinearidade, foi empregada a estatística Variance Inflation Factor (VIF), que expressa o grau no qual cada variável dependente é explicada por outras variáveis, ou seja, o quanto as variáveis do modelo estão relacionadas entre si. Neste estudo, os resultados dos valores VIF de todas as variáveis foram menores do que 2, indicando que não há indícios de multicolinearidade entre as variáveis independentes. A realização desse procedimento se mostra relevante, uma vez que a violação de pressupostos pode indicar distorções nas estimativas dos coeficientes do modelo e, dessa forma, invalidar os resultados da análise.

Conforme as Tabelas 2 e 3, os resultados obtidos suportam parcialmente as duas hipóteses do estudo $\left(H_{1}\right.$ e $\left.H_{2}\right)$. Em relação à $H_{1}$, de que o foco do gestor teria uma relação positiva com a rentabilidade dos fundos, os resultados indicaram que não necessariamente gestores com maior foco em fundos multimercados apresentaram melhor indicador de retorno ajustado ao risco (em média). O foco do gestor, quando avaliado de maneira separada do foco da família (Modelo 2), está positivamente associado com o Índice de Sharpe, mas o seu efeito (em média) não necessariamente é positivo entre os fundos com prêmio pelo risco positivo. Assim, tem-se que o conhecimento obtido com o foco, ao seguir uma estratégia consistente ao longo do tempo, aumentando a experiência e o nível de competência, tende a beneficiar investidores quando considerada a forma tradicional de cálculo do retorno ajustado ao risco (BUSSE, 1999; DELI, 2002; CICCOTELLO; MILES; WALSH, 2006).

No que diz respeito à $H_{2}$, verificou-se, a exemplo de estudos anteriores, que o foco da família de fundo de investimento tem relação positiva com a performance do fundo; ou seja, quanto mais especializada é a família de investimento, melhor tende a ser a sua performance.

Dessa maneira, no período averiguado, as famílias mais especializadas, mesmo como o controle no modelo pelo tamanho das famílias, apresentaram, em média, melhor performance para os referidos fundos que administram. Talvez haja alguma interação entre o foco da família e o foco do gestor do fundo, pois quando considerados de maneira separada, o nível de significância de seus coeficientes sofre alteração. Siggelkow (2003) defende que fundos mútuos pertencentes a famílias especializadas apresentam resultados melhores do que aqueles fundos de famílias menos especializadas (diversificadas). Isso ocorre em razão de as famílias que se especializam em uma pequena linha de produtos conseguirem proporcionar maiores retornos líquidos por desenvolverem melhor as competências e economias de escala ao investirem (CICCOTELLO; MILES; WALSH, 2006). 
Além disso, os resultados evidenciam que o tamanho de um fundo concorre positivamente para o seu desempenho. Ou seja, quanto maior o fundo melhor tende a ser a sua performance. Esse resultado está de acordo com estudos nacionais anteriores de Castro e Minardi (2009) e Guterman (2009), demonstrando que há indícios de assimetria de informação no mercado brasileiro, o que possibilita a obtenção de ganhos anormais. Ademais, os resultados mostraram que, a exemplo do tamanho do fundo, o tamanho da família tem uma relação positiva com a rentabilidade do fundo de investimento (exceto para os casos de fundos com prêmio pelo risco positivo, em que a referida variável não foi estatisticamente significativa).

Ainda no que diz respeito à $H_{2}$, ela também apresenta indícios contrários à HEM em sua forma semiforte, pois quanto maior o foco da família em fundos multimercados, melhor a performance de seus fundos multimercados, o que contraria, pelo menos parcialmente, a Hipótese de Eficiência de Mercado em que os investidores não conseguem auferir retornos superiores ao risco enfrentado por cada ativo com base em informações públicas.

Ademais, verificou-se que a relação entre a idade do fundo e a performance se mostrou negativa para o Índice de Sharpe tradicional, mas positiva para o Índice de Sharpe ajustado, sendo esse resultado parcialmente diferente daqueles resultados obtidos por Dangl e Zechner (2008) e Milani e Ceretta (2013), que observaram um efeito negativo da idade sobre o desempenho. A taxa de administração apresentou um efeito negativo sobre o desempenho dos fundos, indicando que fundos com maiores valores para essas taxas tendem a apresentar menor performance, enquanto que a taxa de performance foi uma variável não significativa para explicar o retorno ajustado ao risco dos fundos da amostra.

\section{CONCLUSÃO}

Considerando a importância do mercado de capitais para a economia e o desenvolvimento de um país e o crescimento expressivo da indústria de fundos brasileira nos últimos anos, no presente estudo analisou-se a performance de 2.942 fundos multimercados no período de janeiro de 2012 a dezembro de 2015, a fim de verificar a relação entre o foco do gestor e a performance do fundo. Verificou-se, também, a relação entre o foco da família e o desempenho do fundo.

Os resultados demonstram que o foco do gestor apresentou relação positiva com a performance dos fundos quando considerado o Índice de Sharpe tradicional; porém, quando considerada uma subamostra contendo fundos com prêmio pelo risco 
positivo, não necessariamente os gestores mais focados foram aqueles com melhor indicador de retorno ajustado ao risco (em média). Em relação ao foco e ao tamanho da família, os coeficientes indicaram uma relação positiva entre ambos e a performance. Embora as estatísticas para o fator de inflação de variância não terem indicado evidências de multicolinearidade, observou-se uma potencial interação entre as variáveis foco do gestor e foco da família. Assim, pode ser que o efeito decorrente do foco do gestor já esteja de alguma maneira refletido no foco ou mesmo no tamanho da família da qual o fundo faz parte, o que apresenta oportunidades para novas pesquisas sobre o assunto.

Quanto às variáveis de controle, observou-se que fundos maiores e fundos pertencentes a famílias maiores apresentaram melhores indicadores de performance. Por outro lado, fundos com maior taxa de administração apresentaram menor retorno ajustado ao risco. Um potencial argumento indicando que taxas de performance podem funcionar como incentivo à gestão não parece aderir à amostra de fundos utilizada neste estudo, o que pode apresentar algum efeito também decorrente do período estudado.

É importante ressaltar duas limitações deste estudo. A primeira está no fato de a análise dos dados basear-se apenas em fundos com dados completos disponíveis para o período estudado. Assim, não foi considerado o controle pelo viés de sobrevivência, pois os fundos que fecharam durante esse período foram excluídos da amostra (bem como aqueles fundos que iniciaram suas atividades durante o período). O período de estudo também representa uma limitação. Contudo, ampliar o período de estudo poderia indicar a necessidade de reduzir a quantidade de fundos com dados completos.

Em trabalhos futuros, sugere-se o estudo sobre famílias e gestores de fundos em outros países da América Latina, onde o nível de eficiência informacional pode ser equivalente ao observado no mercado brasileiro. Novos estudos podem também analisar se os resultados obtidos nesta pesquisa são sensíveis a diferentes medidas para o foco do gestor e o da família, bem como para o retorno ajustado ao risco, uma vez que a alteração na forma de se estimar o Índice de Sharpe promoveu diferenças nos coeficientes obtidos. A abordagem de outras categorias em novas amostras pode também ser objeto de estudo em novas pesquisas, englobando, por exemplo, fundos de renda fixa e fundos de ações. Sugere-se, ainda, que trabalhos futuros analisem se o foco do gestor proporciona também algum efeito na demanda dos investidores pelos fundos de gestores mais especializados. 


\section{REFERÊNCIAS}

ABAD, D.; RUBIA, A. Modelos de estimación de la probabilidad de negociación informada: una comparación metodológica en el mercado español. Revista de Economía financiera, n. 7, p. 26-53, 2005.

ACKERMANN, C.; MCENALLY, R.; RAVENSCRAFT, D. The Performance of Hedge Funds: risk, return, and incentives. The Journal of Finance, v. 54, i. 3, p. 833-874, 1999.

AGARWAL, V.; NAIK, N. Y. Multi-Period Performance Persistence Analysis of Hedge Funds. The Journal of Financial and Quantitative Analysis, v. 35, i. 3, p. 327-342, 2000.

AMIN, G. S.; KAT, H. M. Hedge Fund Performance 1990-2000: Do the "Money Machines” Really Add Value? Journal of Financial and Quantitative Analysis, v. 38, i. 2, p. 251-274, 2003.

ASSOCIAÇÃO BRASILEIRA DAS ENTIDADES DOS MERCADOS FINANCEIRO E DE CAPITAIS. Indústria de Fundos de Investimentos. (Anuário 2015). Disponível em: <http:// http://www.anbima.com.br/anuariodefundos/2015/arqs/anuario2015.pdf >. Acesso em: 05 out. 2015.

BENCIVENGA, V. R.; SMITH, B. D. Financial Intermadiation and Endogenous Growth. The Review of Economic Studies, v. 58, i. 2, p. 195-209, 1991.

BLACK, B. S.; CARVALHO, A. G.; SAMPAIO, J. O. The evolution of corporate governance in Brazil. Emerging Markets Review, v. 20, p. 176-195, 2014.

BOLLEN, N. P. B.; BUSSE, J. A. Short-term persistence in mutual fund performance. The Review of Financial Studies, v. 18, n. 2, p. 569-597, 2005.

BRESSAN, V. G. F. et al. Rentabilidade e assimetria de informação em empresas selecionadas da Bovespa. Revista Ciências Administrativas, v. 13, n. 2, p. 233233, 2007.

BRYANT, L. L. "Down but Not Out" mutual fund manager turnover within fund families. Journal of Financial Intermediation, v. 21, i. 4, p. 569-593, 2012.

BUSSE, J. A. Volatility timing in mutual funds: Evidence from daily returns. Review of Financial Studies, v. 12, i. 5, p. 1009-1041, 1999. 
CAMARGOS, M. A.; ROMERO, J. A. R. Análise Empírica da Reação do Mercado de Capitais Brasileiro a Eventos Corporativos: Teste Conjunto da Hipótese de Eficiência de Mercado. Revista de Gestão USP, São Paulo, v. 13, n. 3, p. 57-74, 2006.

CASTRO, B. R.; MINARDI, A. M. A. F. Comparação do desempenho dos fundos de ações ativos e passivos. Revista Brasileira de Finanças, v. 7, n. 2, p. 143-161, 2009.

CHEVALIER, J.; ELLISON, G. Risk Taking by Muual Funds as a Response to Incentives. Journal of Political Economy, v. 105, n. 6, p. 1167-1200, 1997.

CHI, J.; YANG, J.; YOUNG, M. Mutual funds’ holdings and listed firms’ earnings management: Evidence from China. Journal of Multinational Financial Management, v. 28, p. 62-78, 2014.

CICCOTELLO, C. S.; MILES, J. A.; WALSH, L. S. Should investors choose funds from focused families? Financial Services Review, v. 15, i. 3, p. 247-264, 2006.

CLARE, A. et al. What impact does a change of fund manager have on mutual fund performance? International Review of Financial Analysis, v. 35, p. 167-177, 2014.

COPELAND, T. E.; WESTON, J. F.; SHASTRI, K. Financial theory and corporate policy. 4. ed. EUA: Addison Wiley Publishing Company, 2005.

DANGL, T.; WU, Y.; ZECHNER, J. Market Discipline and Internal Governance in the Mutual Fund Industry. Review of Financial Studies, v. 21, i. 5, p. 2307-2343, 2008.

DAVIS, E. P. Institutional investors, financial market efficiency, and financial stability. European Investment Bank (EIB) papers, v. 8, i. 1, p. 77-107, 2003.

DELI, D. N. Mutual fund advisory contracts: An empirical investigation. Journal of Finance, v. 57, i. 1, p. 109-133, 2002.

EID JUNIOR, W.; SECURATO, J. R. Financial Markets Development: Evidence for Brazil, India and China. Version: 2010. Disponível em: <http://www.ssrn.com/>. Acesso em: 08 out. 2015.

ELTON, E. J.; GRUBER, M. J.; BLAKE, C. R. Incentive fees and mutual funds. The Journal of Finance, v. 58, i. 2, p. 779-804, 2003. 
FAMA, E. F. Efficient Capital Markets: A Review of Theory and Empirical Works. The Journal of Finance, v. 25, i. 2, p. 383-417, 1970.

FAMA, E. F. Efficient Capital Markets: II. The Journal of Finance, v. 46, i. 5, 1991.

GOMES, F. A. R.; CRESTO, V. Avaliação do Desempenho dos Fundos Long-Short no Brasil. Revista Brasileira de Finanças, v. 8, n. 4, p. 505-529, 2010.

GUTERMAN, M. A Relação Convexa entre Desempenho e Captação de Fundos de Investimento no Brasil. 2009. Dissertação (Mestrado em Economia)-Instituto de Ensino e Pesquisa, São Paulo, 2009.

HEALY, P. M.; PALEPU, K. G. The effect of firms' financial disclosure strategies on stock prices. Accounting Horizons, v. 7, i. 1, p. 1-11, 1993.

HU, J.; CHANG, T. Decomposition of mutual fund underperformance. Applied Financial Economics Letters, v. 4, i. 5, p. 363-367, 2008.

HU, J.; YU, H.; WANG, Y. Manager Attributes and Fund Performance: Evidence from Taiwan. Journal of Applied Finance \& Banking, v. 2, i. 4, p. 85-101, 2012.

INTERNATIONAL MONETARY FUND. World Economic Outlook Database. Oct. 2015. Disponível em: <http://www.imf.org/external/pubs/ft/weo/2015/02/pdf/ text.pdf>. Acesso em: 15 dez. 2015.

IQUIAPAZA, R. A. et al. Condicionantes do crescimento dos fundos mútuos de renda fixa no Brasil. Revista de Administração, São Paulo, v. 43, n. 3, p. 250-262, 2008.

IQUIAPAZA, R. A. Performance, captação e foco das famílias de fundos de investimento. 2009. 172 p. Tese (Doutorado em Administração)-Universidade Federal de Minas Gerais, Belo Horizonte, 2009.

ISRAELSEN, C. A refinement to the Sharpe ratio and information ratio. Journal of Asset Management, v. 5, i. 6, p. 423-427, 2005.

JENSEN, M. C.; MECKLING, W. H. Theory of the firm: Managerial behavior, agency costs and ownership structure. Journal of financial economics, v. 3, i. 4, p. 305-360, 1976. 
JIAO, Y.; YE, P. Mutual fund herding in response to hedge fund herding and the impact on stock prices. Journal of Banking and Finance, v. 49, p. 131-148, 2014.

JOAQUIM, G. P. G.; MOURA, M. L. Performance and persistence of Brazilian hedge funds during the financial crisis. Brazilian Review of Finance, v. 9, i. 4, p. 525-548, 2011.

KEMPF, A.; RUENZI, S. Family matters: rankings within fund families and fund inflows. Journal of Business Finance \& Accounting, v. 35, i. 12, p. 177-199, 2008.

LANZANA, A. P. Relação entre disclosure e governança corporativa das empresas brasileiras. 2004. 165 p. Dissertação (Mestrado em Administração)-Universidade de São Paulo, São Paulo, 2004.

LI, H.; ZHANG, X.; ZHAO, R. Investing in Talents: Manager Characteristics and Hedge Fund Performances. Journal of Financial and Quantitative Analysis, v. 46, p. 59-82, 2011.

MALAQUIAS, R. F. Desempenho de Fundos Multimercados. 2012. 102 p. Tese (Doutorado em Administração de Empresas)-Fundação Getúlio Vargas, São Paulo, 2012.

MALAQUIAS, R. F.; EID JUNIOR, W. Eficiência de Mercado e Desempenho de Fundos Multimercados. Revista Brasileira de Finanças, v. 11, n. 1, p. 119-142, 2013.

MALAQUIAS, R. F.; EID JUNIOR, W. Fundos Multimercados: Desempenho, Determinantes do Desempenho e Efeito Moderador. Revista de Administração Mackenzie, v. 15, n. 4, p. 135-163, 2014.

MARKOWITZ, H. Portfolio selection. The journal of finance, v. 7, i. 1, p. 77-91, 1952.

MASSA, M. Why so many mutual funds? Mutual fund families, market segmentation and financial performance. 1998. Disponível em: <http://faculty.insead. edu/massimo-massa/documents/why\%20so\%20many\%20mutual\%20funds.pdf > . Acesso em: 15 dez. 2015.

MILANI, B.; CERETTA, P. S. Tamanho e rentabilidade dos fundos brasileiros de investimento em ações. Revista Alcance, v. 19, n. 4, p. 461-475, 2013. 
NARAYAN, P. K.; NARAYAN, S.; PRABHEESH, K. P. Stock returns, mutual fund flows and spillover shocks. Pacific-Basin Finance Journal, v. 29, p. 146-162, 2014.

OLIVEIRA FILHO, E. C. de. Desempenho de fundos de investimento em ações brasileiros. 2008. 111 p. Dissertação (Mestrado em Administração de Empresas)Fundação Getúlio Vargas, São Paulo, 2008.

PRATHER, L.; BERTIN, W. J.; HENKER, T. Mutual fund characteristics, managerial attributes, and fund performance. Review of Financial Economics, v. 13, i. 4, p. 305-326, 2004.

ROCHMAN, R. R.; EID JUNIOR, W. Fundos de investimento ativos e passivos no Brasil: comparando e determinando os seus desempenhos. In: ENCONTRO NACIONAL DA ASSOCIAÇÃO NACIONAL DE PÓS-GRADUAÇÃO E PESQUISA EM ADMINISTRAÇÃO, 30., 2006, Salvador. Anais... Salvador: Anpad, 2006.

ROCHMAN, R. R.; EID JUNIOR, W. Insiders conseguem retornos anormais? Estudos de eventos sobre as operações de insiders das empresas de governança corporativa diferenciada da Bovespa. In: $7^{\circ}$ Encontro Brasileiro de Finanças, 7., 2007, São Paulo. Anais... São Paulo: SBFin, 2007.

SIGGELKOW, N. Why focus? A study of intra-industry focus effects. The Journal of Industrial Economics, v. 51, i. 2, p. 121-150, 2003.

TIZZIANI, E. et al. The Disposition Effect in the Brazilian Equity Fund Industry. Brazilian Review of Finance, v. 8, i. 4, p. 383-416, 2010.

ZENG, Y.; YUAN, Q.; ZHANG, J. Blurred Stars: Mutual fund ratings in the shadow of conflicts of interest. Journal of Banking and Finance, v. 60, p. 284-295, 2015.

\section{Como citar este artigo:}

ABNT

MOREIRA, Patrycia Olivo; TAVARES, Vitor Borges; MALAQUIAS, Rodrigo Fernandes. Performance e foco do gestor em fundos multimercados. RACE, Revista de Administração, Contabilidade e Economia, Joaçaba: Ed. Unoesc, v. 16, n. 2, p. 633-654, maio/ago. 2017. Disponível em: <http://editora.unoesc.edu.br/index.php/ race $>$. Acesso em: dia/mês/ano. 
Patrycia Olivo Moreira, Vitor Borges Tavares, Rodrigo Fernandes Malaquias

\begin{abstract}
APA
Moreira, P. O., Tavares, V. B., \& Malaquias, R. F. (2017). Performance e foco do gestor em fundos multimercados. RACE, Revista de Administração, Contabilidade e Economia, 16(2), 633-654. Recuperado em dia/mês/ano, de http://editora.unoesc. edu.br/index.php/race
\end{abstract}

